Supplemental Information for:

\title{
Bioinformatic and Reactivity-Based Discovery of Linaridins
}

Matthew A. Georgiou ${ }^{\dagger}$, Shravan R. Dommaraju ${ }^{\ddagger}$, Xiaorui Guo ${ }^{\ddagger}$, David H. Mast ${ }^{\ddagger}$ and Douglas A. Mitchell ${ }^{\dagger *}$

${ }^{\dagger}$ Department of Microbiology, ${ }^{\ddagger}$ Department of Chemistry, University of Illinois at Urbana-Champaign, 600 South Mathews Avenue, Urbana, Illinois 61801, United States.

*corresponding author

Phone: 1-217-333-1345; Fax: 1-217-333-0508; E-mail: douglasm@illinois.edu

Address: 600 South Mathews Avenue, Urbana, Illinois 61801, USA.

ORCID: 0000-0002-9564-0953

\section{Table of Contents}

Experimental Methods

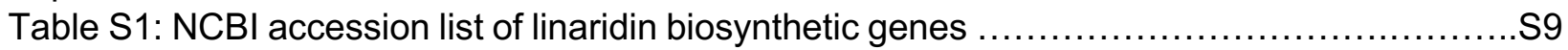

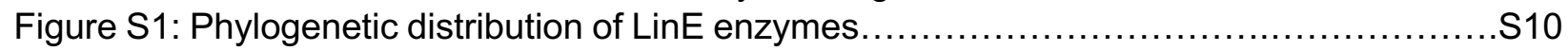

Figure S2: Phylogenetic relation of LinE proteins to known members $\ldots \ldots \ldots \ldots \ldots \ldots \ldots \ldots \ldots . . . \ldots 11$

Note S1: Parsing script for pHMM-based sequence excision....................................

Table S2: Features and weights used in RODEO linaridin module scoring ....................... 13

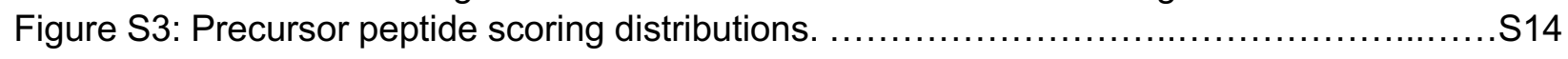

Figure S4: Evaluation of scoring procedure for precision and recall.......................... 15

Table S3: Comparison of RODEO scoring to other bioinformatic tools......................... 16

Figure S5: RODEO scoring of previously identified linaridin precursor peptides................S17

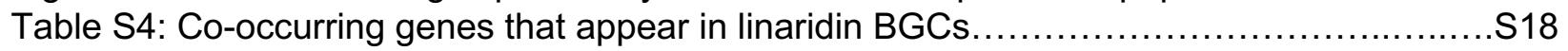

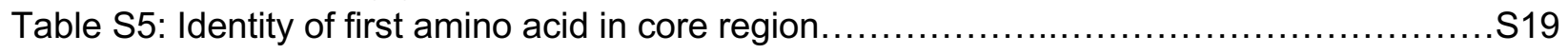

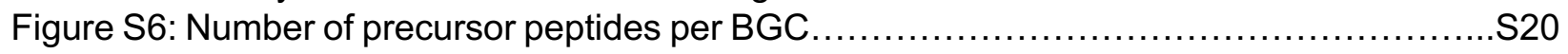

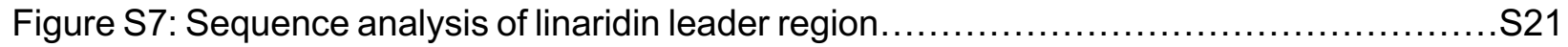

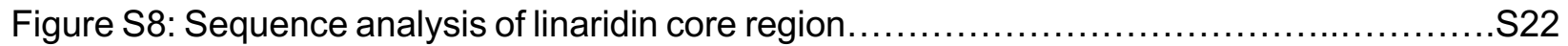

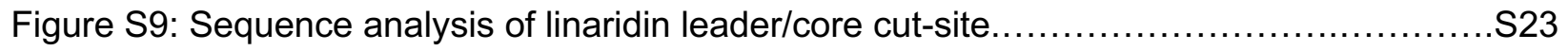

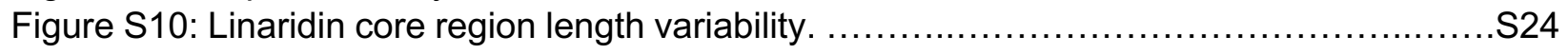

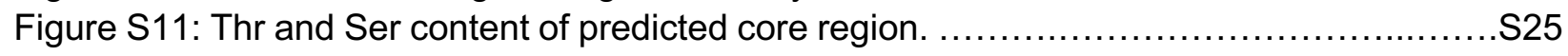

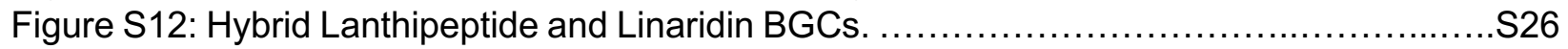

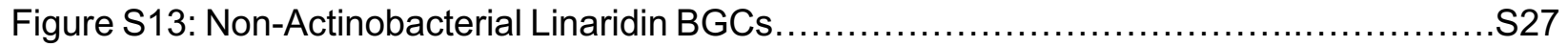

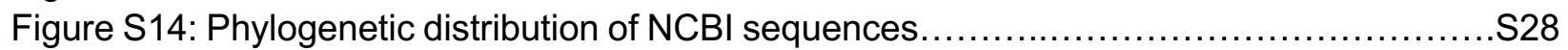

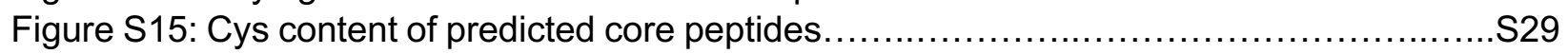

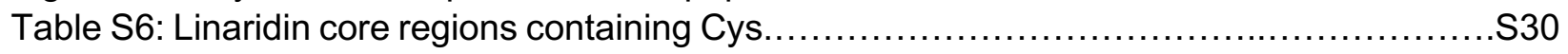

Table S7: List of bacterial strains evaluated for linaridin production ............................ 31

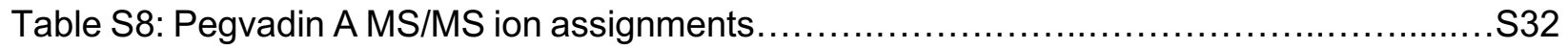

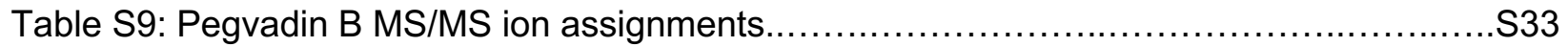

Figure S16: High-resolution and tandem mass spectrometry of pegvadins A and B...........S34

Table S10: Sequence identity/similarity of proteins in linaridin BGCs......................... 35

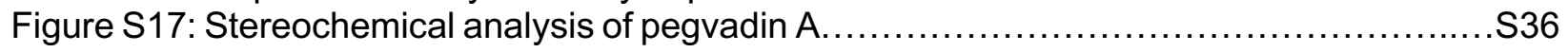

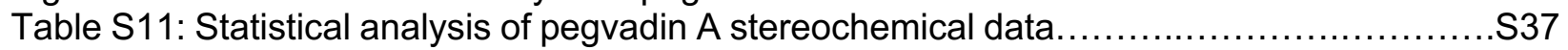

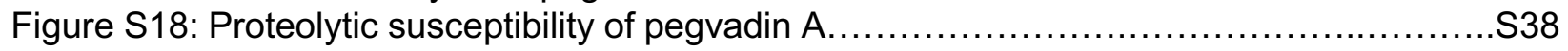

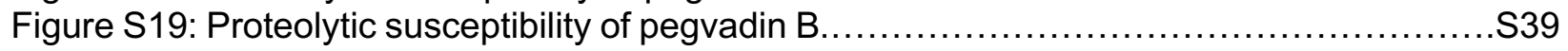

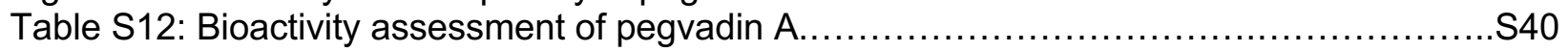

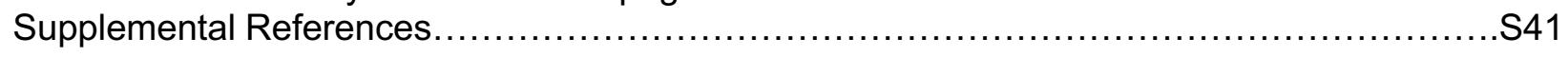




\section{Experimental Methods}

General. Materials and reagents were purchased from Gold Biotechnology, Fisher Scientific, or Sigma Aldrich unless otherwise noted. Matrix-assisted laser desorption/ionization time-of-flight mass spectrometry (MALDI-TOF-MS) analysis was performed using a Bruker UltrafleXtreme MALDI-TOF-TOF mass spectrometer (Bruker Daltonics) in reflector positive mode at the University of Illinois School of Chemical Sciences Mass Spectrometry Laboratory. High-resolution and tandem MS analyses were performed using a ThermoFisher Scientific Orbitrap Fusion instrument equipped with an Advion TriVersa Nanomate 100.

Bioinformatic mining of linaridin BGCs. To identify potential linaridin biosynthetic enzymes, PSI-BLAST $^{1}$ (Position-Specific Iterative - Basic Local Alignment Search Tool) searches were conducted in May 2020 on all predicted key linaridin biosynthetic enzymes (Table S1) with a 0.05 expectation value threshold. Upon removing redundancies, four iterations retrieved 8,000 protein sequences, which were then submitted to the automated ribosomally synthesized posttranslationally modified peptide (RiPP) genome-mining platform, Rapid ORF Description \& Evaluation Online (RODEO; http://ripp.rodeo) ${ }^{2}$. Custom profile Hidden Markov Models (pHMMs) used are provided in Supplemental Dataset 1 while tabular and graphical RODEO output are provided in Supplemental Datasets 2-3. These data were then further analyzed by determining co-localization to homologs of other genes found in the identified linaridin BGCs, particularly genes annotated as linaridin precursors. Initial compilation of accessions produced a dataset of 320 potential linaridin BGCs. Additional linaridin BGCs were identified using the $\mathrm{HMMER}^{3}$ hmmsearch web tool provided by the EMBL-EBI website (https://www.ebi.ac.uk/). ${ }^{3}$ This webtool enabled the use of custom pHMMs to search for LinA and LinL homologs, and results from the search were compared to the original dataset. After BGCs with identical genes and from the same species were removed, 382 linaridin BGCs were cataloged in the final dataset.

Gene annotation using custom HMMs. To aid in bioinformatic discovery, custom pHMM were utilized. Protein sequences were aligned using the Multiple Alignment using/by Fast Fourier Transform (MAFFT). ${ }^{4}$ These alignments were converted into pHMMs using HMMER3. ${ }^{3}$ pHMMs were generated for alignments of key biosynthetic genes that were not identified using preexisting models within the PFAM and TIGRFAM collections. ${ }^{5,6}$ Five custom pHMMs were thus generated for the linaridin-specific RODEO module: LinA, LinE, LinG, LinL, and LinH. To enable pHMM construction, a list of all non-redundant biosynthetic proteins was generated, including manually separating $\mathrm{LinH}$ fusion enzymes from their discretely encoded homologs. This information, when used in combination with RODEO, aided in identifying diverse gene clusters whose gene products retrieved no matches within the PFAM/TIGRFAM databases.

Linaridin precursor peptide scoring. A set of heuristics for linaridin precursor peptide identification were created (Table S2) and then applied to the initial dataset with scoring determined by the relative importance of the trait and its frequency. Sequence motifs identified by the MEME-FIMO ${ }^{7}$ tool were included in the list of heuristic traits.

Heuristics alone did not yield clear separation of manually predicted "valid" linaridin precursors from that of unrelated hypothetical sequences (Figure S3). The application of a support vector machine (SVM) module aided the separation of predicted linaridin precursors from non-linaridin sequences. The addition of a LinA custom pHMM homology metric, with an e-value cutoff of 0.001 , also substantially aided separation between predicted linaridin precursors and non-linaridin sequences. The HMM metric and SVM classification captured overlapping but nonidentical 
subsets of linaridin precursors, so upon the combination of the two with the list of heuristics, the score distribution for predicted linaridins maximally separated from the scoring distribution for other hypothetical sequences (Figure S3).

Sequence similarity network generation. The sequences of precursor peptides within the dataset of potential linaridins were used to construct a sequence similarity network (SSN). ${ }^{8}$ This network allowed the separation of series based on a pre-set alignment score cut off, enabling the assessment of trends within these groupings. All SSNs were generated using the Enzyme Function Initiative Enzyme Similarity Tool (EFI-EST) ${ }^{9}$ (https://efi.igb.illinois.edu/). Visualization was performed using organic layout within Cytoscape. ${ }^{10}$

Phylogenetic tree generation. Phylogenetic trees were generated from the LinE domains of LinE and LinH protein sequences acquired from NCBI accession identifiers. LinE domains were selected from both LinE and LinH homologs with a newly developed parsing script (Supplemental Note S1). The script uses a custom pHMM in combination with a FASTA file as input for an HMMER3 hmmsearch command, ${ }^{3}$ and in this case, the LinE custom pHMM and a FASTA file with all LinE and LinH proteins were used as input. The script parses the hmmsearch output to identify the homologous region to the pHMM from each sequence in the FASTA file. The output is a multiple sequence alignment-ready FASTA file with the aforementioned homologous regions. Multiple sequence alignment was performed by MAFFT. ${ }^{4}$ The tree was built using FastTree ${ }^{11}$ software using the JTT+CAT amino acid revolution model. For tree visualization, we used the interactive Tree of Life (iTOL) website (http://itol.embl.de/). ${ }^{12}$ Supplemental Dataset 5 includes a phyloXML formatted text file for regenerating the LinE phylogenetic tree.

Biosynthetic gene analysis. Interpro ${ }^{13}$ (https://www.ebi.ac.uk/interpro) and HHPred ${ }^{14}$ (https://toolkit.tuebingen.mpg.de/tools/hhpred) were used to identify discernable protein domains within the three key biosynthetic genes. As in previous studies, it was determined that the LinE protein resembled protein domains corresponding to an $\alpha / \beta$ hydrolase protein, the LinG protein resembles a transmembrane protein, and the LinL protein contains both a signal peptide domain and non-cytoplasmic domain. ${ }^{15}$

Bacterial cultivation. Eight media for Actinomycetes were screened, including: AGS, ATCC 172, Alternative Mannitol-Soy, C-Food, GUBC, ISP2, ISP4, and V8. ${ }^{16}$ Recipes for each of medium are provided on the next page. Previous studies have indicated that growth on different media containing different carbon sources and metal ion concentrations can elicit the production of secondary metabolites. ${ }^{17}$ Target strains were initially grown on ATCC 172 media (pH 7.0). Plates were incubated at $30{ }^{\circ} \mathrm{C}$ until sporulation was evident or until $14 \mathrm{~d}$ had passed. Next, liquid cultures of ATCC $172(\mathrm{pH} \mathrm{7.2)}$ were inoculated with spores or single colonies and allowed to grow at $30{ }^{\circ} \mathrm{C}$ in a drum roller $(40 \mathrm{rpm})$ for $7 \mathrm{~d}$. Finally, the bacterial culture $(100 \mu \mathrm{L})$ was inoculated onto each screening medium. Each sample was cultivated at $30^{\circ} \mathrm{C}$ for $10 \mathrm{~d}$ and $18 \mathrm{~d}$. 


\section{Medium Ingredients}

\begin{tabular}{|c|c|c|}
\hline Medium & Ingredients & Amount / L (g) \\
\hline \multirow[t]{6}{*}{ ATCC 172} & Soluble Starch & 20 \\
\hline & Dextrose & 10 \\
\hline & Yeast Extract & 5 \\
\hline & $\mathrm{N}$-Z Amine & 5 \\
\hline & $\mathrm{CaCO}_{3}$ & 1 \\
\hline & $\mathrm{pH}$ to 7.2 & \\
\hline \multirow[t]{10}{*}{ ISP4 } & Soluble Starch & 10 \\
\hline & $\mathrm{K}_{2} \mathrm{HPO}_{4}$ & 1 \\
\hline & $\mathrm{Mg}_{2} \mathrm{SO}_{4} \cdot 7 \mathrm{H}_{2} \mathrm{O}$ & 1 \\
\hline & $\mathrm{NaCl}$ & 1 \\
\hline & Ammonium Sulfate & 2 \\
\hline & $\mathrm{CaCO}_{3}$ & 2 \\
\hline & $\mathrm{FeSO}_{4} .7 \mathrm{H}_{2} \mathrm{O}$ & 0.001 \\
\hline & $\mathrm{ZnSO}_{4} .7 \mathrm{H}_{2} \mathrm{O}$ & 0.001 \\
\hline & $\mathrm{MnCl}_{2} \cdot 2 \mathrm{H}_{2} \mathrm{O}$ & 0.001 \\
\hline & $\mathrm{pH}$ to 7.2 & \\
\hline \multirow[t]{3}{*}{ Alt-MS } & Mannitol & 10 \\
\hline & Malt Extract & 10 \\
\hline & Soy Flour & 10 \\
\hline \multirow[t]{8}{*}{ GUBC } & Glycerol & $5 \mathrm{~mL}$ \\
\hline & Sucrose & 10 \\
\hline & Beef Extract & 5 \\
\hline & Casamino Acids & 5 \\
\hline & Solution A & $5 \mathrm{~mL}$ \\
\hline & Solution B & $2 \mathrm{~mL}$ \\
\hline & after autoclaving: & \\
\hline & Balch's Vitamins & $10 \mathrm{~mL}$ \\
\hline \multirow[t]{3}{*}{ ISP2 } & Yeast Extract & 4 \\
\hline & Malt Extract & 10 \\
\hline & Dextrose & 4 \\
\hline \multirow[t]{10}{*}{ AGS } & Arginine $\mathrm{HCl}$ & 1 \\
\hline & Glycerol & 12.5 \\
\hline & $\mathrm{K}_{2} \mathrm{HPO}_{4}$ & 1 \\
\hline & $\mathrm{NaCl}$ & 1 \\
\hline & $\mathrm{Mg}_{2} \mathrm{SO}_{4} .7 \mathrm{H}_{2} \mathrm{O}$ & 0.5 \\
\hline & $\mathrm{Fe}_{2}\left(\mathrm{SO}_{4}\right)_{3} .6 \mathrm{H}_{2} \mathrm{O}$ & 0.01 \\
\hline & $\mathrm{CuSO}_{4} .5 \mathrm{H} 2 \mathrm{O}$ & 0.001 \\
\hline & $\mathrm{MnSO} 4 . \mathrm{H} 2 \mathrm{O}$ & 0.001 \\
\hline & $\mathrm{ZnSO}_{4} .7 \mathrm{H}_{2} \mathrm{O}$ & 0.001 \\
\hline & $\mathrm{pH}$ to 7.0 & \\
\hline Adapted & Dextrose & 25 \\
\hline TVA1 & Fish Meal & 15 \\
\hline \multirow[t]{3}{*}{ Medium } & Yeast Extract & 2 \\
\hline & $\mathrm{CaCO}_{3}$ & 4 \\
\hline & $\mathrm{pH}$ to 7.2 & \\
\hline \multirow[t]{2}{*}{ V8 } & V8 Juice & $200 \mathrm{~mL}$ \\
\hline & $\mathrm{CaCO}_{3}$ & 3 \\
\hline
\end{tabular}

\section{Component Recipes}

\begin{tabular}{|c|c|c|}
\hline Solution name & Ingredients & Amount / L (g) \\
\hline \multirow[t]{2}{*}{ Solution A } & $1 \mathrm{M} \mathrm{Na}_{2} \mathrm{HPO}_{4}$ & $833 \mathrm{~mL}$ \\
\hline & $1 \mathrm{M} \mathrm{KH}_{2} \mathrm{PO}_{4}$ & $167 \mathrm{~mL}$ \\
\hline \multirow[t]{5}{*}{ Solution B } & $\mathrm{MgSO}_{4} \cdot 7 \mathrm{H}_{2} \mathrm{O}$ & 59.3 \\
\hline & $\mathrm{CaCl}_{2} \cdot 2 \mathrm{H}_{2} \mathrm{O}$ & 6.67 \\
\hline & $\left(\mathrm{NH}_{4}\right)_{6} \mathrm{Mo}_{7} \mathrm{O}_{24} \cdot 4 \mathrm{H}_{2} \mathrm{O}$ & 0.0185 \\
\hline & $\mathrm{FeSO}_{4} .7 \mathrm{H}_{2} \mathrm{O}$ & 0.198 \\
\hline & Hunter's Metals & $100 \mathrm{~mL}$ \\
\hline \multirow[t]{7}{*}{ Hunter's Metals } & EDTA.2Na & 2.5 \\
\hline & $\mathrm{ZnSO}_{4} .7 \mathrm{H}_{2} \mathrm{O}$ & 10.95 \\
\hline & $\mathrm{FeSO}_{4} .7 \mathrm{H}_{2} \mathrm{O}$ & 5 \\
\hline & $\mathrm{MnSO}_{4} \cdot \mathrm{H}_{2} \mathrm{O}$ & 1.54 \\
\hline & $\mathrm{CuSO}_{4} .5 \mathrm{H}_{2} \mathrm{O}$ & 0.392 \\
\hline & $\mathrm{Co}\left(\mathrm{NO}_{3}\right) 2.6 \mathrm{H}_{2} \mathrm{O}$ & 0.25 \\
\hline & $\mathrm{Na}_{2} \mathrm{~B}_{4} \mathrm{O}_{7} .10 \mathrm{H}_{2} \mathrm{O}$ & 0.177 \\
\hline \multirow[t]{24}{*}{ Balch's Vitamins ${ }^{18}$} & Biotin & 0.002 \\
\hline & Folic Acid & 0.002 \\
\hline & Pyridoxine hydrochloride & 0.01 \\
\hline & Thiamine hydrochloride & 0.005 \\
\hline & Riboflavin & 0.005 \\
\hline & Nicotinic Acid & 0.005 \\
\hline & Calcium pantothenate & 0.005 \\
\hline & Vitamin B12 & 0.01 \\
\hline & p-aminobenzoic acid & 0.005 \\
\hline & Lipoic acid & 0.005 \\
\hline & after autoclaving: & \\
\hline & Nitrilotriacetic acid & 1.5 \\
\hline & $\mathrm{MgSO}_{4} .7 \mathrm{H}_{2} \mathrm{O}$ & 3 \\
\hline & $\mathrm{MnSO}_{4} .2 \mathrm{H}_{2} \mathrm{O}$ & 0.5 \\
\hline & $\mathrm{NaCl}$ & 1 \\
\hline & $\mathrm{FeSO}_{4} .7 \mathrm{H}_{2} \mathrm{O}$ & 0.1 \\
\hline & $\mathrm{CoSO}_{4}$ or $\mathrm{CoCl}_{2}$ & 0.1 \\
\hline & $\mathrm{CaCl}_{2} \cdot 2 \mathrm{H}_{2} \mathrm{O}$ & 0.1 \\
\hline & $\mathrm{ZnSO}_{4}$ & 0.1 \\
\hline & $\mathrm{CuSO}_{4} .5 \mathrm{H}_{2} \mathrm{O}$ & 0.01 \\
\hline & $\mathrm{AlK}\left(\mathrm{SO}_{4}\right)_{2}$ & 0.01 \\
\hline & $\mathrm{H}_{3} \mathrm{BO}_{3}$ & 0.01 \\
\hline & $\mathrm{Na}_{2} \mathrm{MoO}_{4} \cdot 2 \mathrm{H}_{2} \mathrm{O}$ & 0.01 \\
\hline & $\mathrm{pH}$ to 7.0 & \\
\hline
\end{tabular}


Reactivity-based labeling of extracts. Cells from plates were harvested using a sterile razor blade and placed into a $1.7 \mathrm{~mL}$ microfuge tube. $\mathrm{MeOH}(1 \mathrm{~mL})$ was added to each extraction individually with gentle rocking at $25^{\circ} \mathrm{C}$ for $18 \mathrm{~h}$. The $\mathrm{MeOH}$ (cell-surface) extraction from each strain was subjected to reactivity-based labeling using a thiol-functionalized probe. Cellular debris was removed from the extractions by centrifugation $\left(17,000 \times \mathrm{g}, 10 \mathrm{~min}, 25^{\circ} \mathrm{C}\right)$. The soluble fraction was then reacted with $100 \mathrm{mM}$ of dithiothreitol (DTT) and $10 \mathrm{mM} \mathrm{N}, \mathrm{N}$ diisopropylethylamine for $4 \mathrm{~h}$ and $24 \mathrm{~h}$ at $25^{\circ} \mathrm{C}$. The samples were then analyzed by MALDITOF-MS.

MALDI-TOF-MS. Matrix-assisted laser desorption/ionization time-of-flight mass spectrometry (MALDI-TOF-MS) enabled the identification of peaks of interest when compared to predicted masses. Samples were spotted on a stainless-steel MALDI target with $50 \% \mathrm{MeCN}$ saturated with a-cyano-4-hydroxycinnamic acid with $0.1 \%(v / v)$ formic acid. Sample analysis was performed using a Bruker Daltonics UltrafleXtreme MALDI-TOF mass spectrometer in reflector positive mode. After reactivity-based labeling of extracts, this technique allowed the identification of DTT adducts (addition of $154 \mathrm{Da}$ per label).

Large-scale production and purification of pegvadin A and B. Pegvadin A: Streptomyces noursei NRRL B-1714 was grown on Alt-MS medium with $1.5 \%(0.6 \mathrm{mg} / \mathrm{mL})$ agar on $10 \mathrm{~cm}$ sterilized dishes $(n=160)$ at $30{ }^{\circ} \mathrm{C}$ for $11 \mathrm{~d}$. Pegvadin B: Streptomyces auratus NRRL B-8097 was grown on ATCC 172 medium with $1.5 \%(0.6 \mathrm{mg} / \mathrm{mL})$ agar on $10 \mathrm{~cm}$ sterilized dishes $(\mathrm{n}=160)$ at $30{ }^{\circ} \mathrm{C}$ for $11 \mathrm{~d}$. Sporulation was observed on the third day in both cases. Cells were harvested with a sterile razor blade and collectively extracted with $700 \mathrm{~mL}$ of $\mathrm{MeOH}$ with shaking at $25{ }^{\circ} \mathrm{C}$ for $3 \mathrm{~h}$. The methanolic extract was vacuum-filtered, and the remaining cell extract was resuspended in $600 \mathrm{~mL}$ of $\mathrm{MeOH}$. The solution then gently rocked at $25^{\circ} \mathrm{C}$ for $3 \mathrm{~h}$. This extraction process was repeated twice, the methanolic fractions were combined, and $10 \mathrm{~g}$ of Celite 545 adsorbent was added. This mixture was dried using a rotary evaporator.

Pegvadin adsorbed onto the Celite was purified by using a Teledyne Isco Combiflash EZprep equipped with a RediSep Rf C18 cartridge (130 g media, $60 \AA$ pore size, 40-63 $\mu \mathrm{m}$ particle size, 230-400 mesh) using a mobile phase of $10 \mathrm{mM}$ aq. $\mathrm{NH}_{4} \mathrm{HCO}_{3}$ in $\mathrm{MeCN}$ at $75 \mathrm{~mL} \mathrm{~min}^{-1}$ over a gradient from $20-70 \%$. Wavelengths at $220 \mathrm{~nm}$ and $280 \mathrm{~nm}$ were monitored to determine which fractions contained peaks of interest. These fractions were further analyzed via MALDI-TOF-MS before being pooled and dried by rotary evaporation.

Reverse phase purification was performed using a Teledyne Isco Combiflash EZprep equipped with a RediSep Prep C18Aq column (100 A pore size, 40-63 um particle size, 230-400 mesh) using a mobile phase of $10 \mathrm{mM}$ aq. $\mathrm{NH}_{4} \mathrm{HCO}_{3} / \mathrm{MeCN}$ with a gradient from $20 \%$ to $60 \% \mathrm{MeCN}$ over $25 \mathrm{~min}$ at $19 \mathrm{~mL} / \mathrm{min}$. Fractions containing pegvadin were determined through MALDI-TOF analysis. These fractions were combined and dried using a rotary evaporator. A semi-preparative HPLC was then performed using a Perkin Elmer Flexar HPLC equipped with a Betasil C18 (Thermo Scientific) reverse phase column. Pegvadin was dissolved in $8 \mathrm{~mL}$ of $10 \mathrm{mM}$ aq. $\mathrm{NH}_{4} \mathrm{HCO}_{3} / \mathrm{MeCN}$ (70:30), the suspension was then clarified by centrifugation $(17,000 \mathrm{x}$ for 20 min, $25^{\circ} \mathrm{C}$ ) before injection. Pegvadin was purified under the following conditions: solvent $\mathrm{A}$ (10 $\mathrm{mM} \mathrm{NH}_{4} \mathrm{HCO}_{3}$ ), solvent $\mathrm{B}(\mathrm{MeCN})$, flow rate of $4 \mathrm{~mL} / \mathrm{min}$ and the following gradient: $\mathrm{t}=0 \mathrm{~min}, 30 \%$ $\mathrm{B}, \mathrm{t}=7 \mathrm{~min}, 35 \% \mathrm{~B}, \mathrm{t}=40 \mathrm{~min}, 38 \% \mathrm{~B}, \mathrm{t}=50 \mathrm{~min}, 95 \% \mathrm{~B}, \mathrm{t}=55 \mathrm{~min}, 30 \% \mathrm{~B}$. The column was equilibriated at starting conditions for $15 \mathrm{~min}$ before each injection. Following second purificaitons, samples containing pegvadin were once again combined. A final, analytical, purification was performed using the same equipment with an analytical Betasil C18 (Thermo Scientific) reverse 
phase column. Pegvadin was dissolved and clarified once again, as detailed above. Final purification was performed under the following conditions: solvent $A\left(\mathrm{NH}_{4} \mathrm{HCO}_{3}\right)$, solvent $B$ (MeCN), flow rate of $1 \mathrm{~mL} / \mathrm{min}$ and the following gradient: $\mathrm{t}=0 \mathrm{~min}, 30 \% \mathrm{~B}, \mathrm{t}=10 \mathrm{~min}, 39 \% \mathrm{~B}, \mathrm{t}=15$ $\min , 40 \% \mathrm{~B}, \mathrm{t}=20 \mathrm{~min}, 45 \% \mathrm{~B}, \mathrm{t}=26 \mathrm{~min}, 50 \% \mathrm{~B}, \mathrm{t}=30 \mathrm{~min}, 50 \% \mathrm{~B}, \mathrm{t}=35 \mathrm{~min}, 30 \% \mathrm{~B}$. Purified pegvadin was intially dried under rotary evaporation at $25^{\circ} \mathrm{C}$ and then dried to completion using a SpeedVac vacuum concentrator.

HR-ESI-MS/MS analysis of pegvadin A and B. Pegvadin A and B were desalted using a ZipTip and eluted into $75 \%$ aq MeCN supplemented with $0.1 \%$ acetic acid. Samples were directly infused onto a ThermoFisher Scientific Orbitrap Fusion ESI-MS using an Advion TriVersa Nanomate 100. MS calibration was performed with Pierce LTQ Velos ESI Positive Ion Calibration Solution (ThermoFisher). The MS was operated using the following parameters: 100,000 resolution, $2 \mathrm{~m} / \mathrm{z}$ isolation width (MS/MS), 70 normalized collision energy (MS/MS), 0.4 activation q value (MS/MS), and $30 \mathrm{~ms}$ activation time (MS/MS). Fragmentation was performed using collision-induced dissociation (CID) at normalized collision energy. Data analysis was conducted using the Qualbrowser application of Xcalibur software (ThermoFisher Scientific).

Quantitative NMR of pegvadin A. The concentration of post-HPLC pegvadin A was determined via quantitative NMR on a Bruker Carver B500 NMR spectrometer equipped with a $5 \mathrm{~mm}$ broadband Cryoprobe. An unknown amount of pegvadin A was dissolved in $600 \mu \mathrm{L} \mathrm{CD}_{3} \mathrm{OD}$ (Cambridge Isotope Labs, $>99.8 \%$ atom \%D) with a final concentration of $100 \mu \mathrm{M}$ dimethyl terephthalate as calibrant. Samples were held at $25^{\circ} \mathrm{C}$ during acquisition and standard Bruker pulse sequences were used with $30 \mathrm{~s}$ relaxation delay to acquire $1 \mathrm{H}-\mathrm{NMR}$ spectra over 128 scans. Pegvadin A concentrations were determined by comparing the ratios of the dimethyl terephthalate aromatic proton integrals with those of the pegvadin A dehydrobutyrine methine proton integrals. ${ }^{19}$

Marfey's analysis of pegvadin A stereochemistry. Alongside pegvadin A, labeling blanks, consisting of two empty hydrolysis tubes, were tested. After microwave assisted hydrolysis these blanks were reacted with 1-fluoro-2-4-dinitrophenyl-5-L-alanine amide (Marfey's reagent, FDAA) to evaluate baseline levels of amino acids present in the background. A peptide containing all Lamino acids, YLDHLGSSLV, was also hydrolyzed under the same conditions. This was done to suppress racemization during the reaction.

Pegvadin A $(50 \mu \mathrm{g})$ was reconstituted in $200 \mu \mathrm{L}$ of LC-MS grade methanol. The reconstituted pegvadin A was then transferred to a glass hydrolysis tube and methanol was removed by vacuum centrifugation. Microwave-assisted acid hydrolysis was performed using a CEM Discover microwave (CEM corporation).

To intitate the hydrolysis reaction, $5 \mathrm{~mL}$ of $6 \mathrm{M}^{2} \mathrm{HCl}$ in ${ }^{2} \mathrm{H}_{2} \mathrm{O}$ with $0.1 \%$ phenol (unstablized) was used added to the reaction vessel. The vessel was then sealed, and microwave assisted hydrolysis was performed under the following conditions: temperature and pressure were ramped to $165^{\circ} \mathrm{C}$ and $60 \mathrm{PSI}$ in 5 minutes, and then held for 30 minutes. Following the hydrolysis, the vessel was cooled, and excess condensed liquid in glass reaction vials was removed by vacuum centrifugation. The hydrolysate was reconstituted in $55 \mu \mathrm{L}$ of $0.5 \mathrm{M} \mathrm{NaHCO}_{3}$ and sonicated for 30 s. For amino acid derivatization, $20 \mu \mathrm{L}$ of $1 \mathrm{mg} / \mathrm{mL}$ FDAA in $\mathrm{CH}_{3} \mathrm{CN}$ was combined with $25 \mu \mathrm{L}$ of hydrolysate and incubated for $3 \mathrm{~h}$ at $63 \pm 3{ }^{\circ} \mathrm{C}$. Following incubation, the reaction mixture was cooled to room temperature and $10 \mu \mathrm{L}$ was diluted to $200 \mu \mathrm{L}$ with $25 \mathrm{mM} \mathrm{NH}_{4} \mathrm{HCO}_{2}$ in Liquid chromatography (LC)-multiple reaction monitoring (MRM)-mass spectrometry (MS) grade $\mathrm{H}_{2} \mathrm{O}$ 
and $20 \mu \mathrm{L}$ of injected onto the LC. To label amino acid standards, $25 \mu \mathrm{L}$ of amino acid standards (200 $\mu \mathrm{M}$ each amino acid) were combined with $20 \mu \mathrm{L}$ of $1 \mathrm{mg} / \mathrm{mL}$ of FDAA and reacted/analyzed as above. After incubation with FDAA, the labeled L/D AA standards were diluted to $1 \mu \mathrm{M}$ with 25 $\mathrm{mM} \mathrm{NH}_{4} \mathrm{HCO}_{2}$ and $20 \mu \mathrm{L}$ was then injected onto the LC-MS. For labeling blanks, tube contents were reconstituted in $55 \mu \mathrm{L}$ of $500 \mathrm{mM}$ sodium bicarbonate and $25 \mu \mathrm{L}$ was then combined with $20 \mu \mathrm{L}$ of $1 \mathrm{mg} / \mathrm{mL}$ FDAA in $\mathrm{CH}_{3} \mathrm{CN}$. After incubation, the amino acid standards $10 \mu \mathrm{L}$ of the FDAA reacted labeling blank solution was diluted to $200 \mu \mathrm{L}$ with $25 \mathrm{mM} \mathrm{NH}_{4} \mathrm{HCO}_{2}$ and $20 \mu \mathrm{L}$ was injected.

LC-MS analysis was performed using an EVOQ elite, triple quad mass spectrometer equipped with an Elute HT UHPLC (Bruker Daltonic) and a Kinetex Phenyl-Hexyl column (100 Å pore size, $2.6 \mu \mathrm{m}$ particle size, $100 \mathrm{~mm} \times 2.1 \mathrm{~mm}$ ). Amino acids were purified under the following conditions: solvent $\mathrm{A}\left(25 \mathrm{mM} \mathrm{NH}_{4} \mathrm{HCO}_{2}\right)$ and solvent $\mathrm{B}(\mathrm{MeOH})$, flowerate of $0.3 \mathrm{~mL} / \mathrm{min}$ and the following gradient: $\mathrm{t}=0 \mathrm{~min}, 5 \% \mathrm{~B}, \mathrm{t}=2 \mathrm{~min}, 5 \% \mathrm{~B}, \mathrm{t}=7 \mathrm{~min}, 20 \% \mathrm{~B}, \mathrm{t}=12 \mathrm{~min}, 55 \% \mathrm{~B}, \mathrm{t}=15 \mathrm{~min}, 55 \% \mathrm{~B}, \mathrm{t}=18$ $\min , 90 \% B, t=21,90 \% B$.

\begin{tabular}{|c|c|c|c|c|}
\hline \multicolumn{5}{|c|}{ Ions monitored by MRM-MS } \\
\hline $\begin{array}{l}\text { Amino } \\
\text { Acid }\end{array}$ & $\begin{array}{c}\text { Precursor } \\
\mathrm{m} / \mathrm{z}\end{array}$ & $\begin{array}{c}\text { Product } \\
\mathrm{m} / \mathrm{z}\end{array}$ & $\begin{array}{l}\text { Voltage } \\
\text { (V) }\end{array}$ & Mode \\
\hline Ala & 340 & 278.1 & 14 & $(-)$ \\
\hline \multirow{2}{*}{$\operatorname{Arg}$} & 426.9 & 70.1 & 20 & \multirow{2}{*}{$(+)$} \\
\hline & 426.9 & 130.1 & 20 & \\
\hline \multirow[b]{2}{*}{ Asp } & 384.0 & 267.9 & 30 & \multirow[b]{2}{*}{$(-)$} \\
\hline & 384.0 & 207.0 & 30 & \\
\hline Glu & 398.0 & 202.0 & 24 & $(-)$ \\
\hline Gly & 326.1 & 162.0 & 32 & $(-)$ \\
\hline His & 658.2 & 549.1 & 19 & $(-)$ \\
\hline Tyr & 684.1 & 351.9 & 28 & $(-)$ \\
\hline$T y r+2^{a}$ & 686.1 & 353.9 & 27 & $(-)$ \\
\hline Pro & 365.9 & 321.9 & 15 & $(-)$ \\
\hline Leu/lle & 382.0 & 319.8 & 18 & $(-)$ \\
\hline Val & 367.9 & 306.0 & 15 & $(-)$ \\
\hline Ser & 355.9 & 263.9 & 16 & $(-)$ \\
\hline Lys & 649.1 & 479.1 & 36 & $(-)$ \\
\hline
\end{tabular}

Reaction conditions for peptidase digestions of pegvadin A \& B. Peptidase digests were performed on both pegvadin $A$ and $B$ to reaffirm the presence of $D$-amino acids predicted by the Marfey's analysis. The general reaction conditions were $5 \mu \mathrm{L}$ of $0.4 \mu \mathrm{g} / \mu \mathrm{L}$ pegvadin $\mathrm{A} / \mathrm{B}, 1 \mu \mathrm{L}$ of $100 \mathrm{ng} / \mathrm{uL}$ peptidase, $14 \mu \mathrm{L}$ of each respective buffer. These were incubated at $37^{\circ} \mathrm{C}$ for $4 \mathrm{~h}$ and $24 \mathrm{~h}$, with analysis performed by MALDI-TOF-MS at each timepoint.

Peptidases utilized and their respective buffers were: Endoprotease Asp-N in New England Biolabs (NEB) AspN Reaction Buffer, Creative Biolabs carboxypeptidase $Y$ in piperazine-N,N'bis(2-ethanesulfonic acid (PIPES) buffer, GluC in NEB GluC Reaction Buffer and Promega trypsin gold in Tris buffer. 
Evaluation of pegvadin A antibiotic activity. Pseudomonas aeuroginosa PAO1, Straphylococcus aureus USA300, Microccocus luteus DSM 1790, Streptomyces puniceus NRRL B-2895 were grown in $10 \mathrm{~mL}$ of brain-heart infusion (BHI) medium at $37^{\circ} \mathrm{C}(P$. aeuroginosa and $S$. aureus) and $30^{\circ} \mathrm{C}$ (M. luteus and S. puniceus). The cultures were adjusted to an optical density at $600 \mathrm{~nm}\left(\mathrm{OD}_{600}\right)$ of $0.015 \mathrm{in} \mathrm{BHI}$ medium with $100 \mu \mathrm{L}$ being added to 96-well microplates. Successive two-fold dilutions of pegvadin A in $99.5 \% \mathrm{BHI}$ and $0.5 \% \mathrm{DMSO}(\mathrm{v} / \mathrm{v})$ were added to the cultures $(0.03-32 \mu \mathrm{g} / \mathrm{mL})$. As a positive control, tetracyclin, chloramphenicol, or kanamycin (0.03-32 $\mu \mathrm{g} / \mathrm{mL}$ ) were used, depending on the bacterium (Table S12). As a negative control, $0.5 \%$ $(v / v)$ DMSO was added to each culture. Plates containing $P$. aeuroginosa and $S$. aureus were incubated at $37^{\circ} \mathrm{C}$ for $28 \mathrm{~h}$. Plates containing M. luteus and S. puniceus were incubated at $30^{\circ} \mathrm{C}$ for $72 \mathrm{~h}$. The minimum inhibitory concentration (MIC) reported are values which surpressed all visible growth $(n=9)$. 
Table S1: NCBI accession list of linaridin biosynthetic genes. The NCBI accession identifiers of all genes referenced directly in the main text. Associated PFAM and TIGRFAM models as referenced as well as any custom pHMM (Supplemental Dataset 1) for detection of remote sequence homology.

\begin{tabular}{|c|c|c|}
\hline Protein & PFAM/TIGRFAM/pHMM & NCBI Accession ID \\
\hline СурA & $\operatorname{Lin} A$ & ADR72962.1 \\
\hline СурH & $\mathrm{LinH}$ & ADR72963.1 \\
\hline CypL & LinL & ADR72964.1 \\
\hline CypD & Decarboxylase (TIGR00521) & ADR72965.1 \\
\hline СурM & Methyltransferase (PF13649) & ADR72966.1 \\
\hline СурT & ABC Transporter (TIGR02857) & ADR72967.1 \\
\hline СурP & Unknown & ADR72968.1 \\
\hline Cypl & DUF255 (PF03190) & ADR72969.1 \\
\hline LegT & ABC Transporter (TIGR02204) & WP_052230046.1 \\
\hline LegC & Desaturase (TIGR02734) & WP_043270372.1 \\
\hline LegM & Methyltransferase (PF13649) & WP_107068144.1 \\
\hline LegE & LinE & WP 078894000.1 \\
\hline LegF & LinL & WP 078894692.1 \\
\hline LegA & Lin $A$ & WP 107068145.1 \\
\hline LegH & LinG & WP_043265482.1 \\
\hline GrmA & $\operatorname{Lin} A$ & WP_003970682.1 \\
\hline GrmH & $\mathrm{LinH}$ & BAG23194.1 \\
\hline GrmL & LinL & BAG23193.1 \\
\hline GrmD & Decarboxylase (TIGR02857) & BAG23192.1 \\
\hline GrmM & Methyltransferase (PF13649) & BAG23191.1 \\
\hline GrmT & ABC Transporter (TIGR02857) & BAG23190.1 \\
\hline GrmP & Unknown & BAG23189.1 \\
\hline $\operatorname{Sin} A$ & $\operatorname{Lin} A$ & WP 101256403.1 \\
\hline $\mathrm{SinH}$ & $\mathrm{LinH}$ & WP 101256404.1 \\
\hline $\operatorname{SinL}$ & LinL & WP 101256405.1 \\
\hline SinD & Decarboxylase (TIGR00521) & WP 101256406.1 \\
\hline $\operatorname{Sin} M$ & Methyltransferase (PF13649) & WP 101256407.1 \\
\hline SinT & ABC Transporter (TIGR02857) & WP 101256408.1 \\
\hline SinP & Unknown & WP 101256409.1 \\
\hline MonA & LinA & WP 030019228.1 \\
\hline MonT & ABC Transporter (TIGR02204) & WP_078624127.1 \\
\hline MonC & Desaturase (TIGR03467) & WP_050502300.1 \\
\hline MonM & Methyltransferase (PF13649) & WP_030019231.1 \\
\hline MonK & Helix-turn-helix (PF13518) & WP_078624119.1 \\
\hline MonE & LinE & WP 078624126.1 \\
\hline MonL & LinL & WP 050502306.1 \\
\hline MonG & LinG & WP_030019227.1 \\
\hline PvaA & Lin $A$ & ANZ17121.1 \\
\hline PvaT & ABC Transporter (TIGR02204) & ANZ17127.1 \\
\hline PvaC & Desaturase (TIGR03467) & ANZ17126.1 \\
\hline PvaM & Methyltransferase (PF13649) & ANZ17125.1 \\
\hline PvaK & Helix-turn-helix (PF13518) & ANZ17124.1 \\
\hline PvaE & LinE & ANZ17123.1 \\
\hline PvaL & LinL & ANZ17122.1 \\
\hline PvaG & LinG & ANZ17120.1 \\
\hline PvbA & $\operatorname{Lin} A$ & WP 099053532.1 \\
\hline PvbT & ABC Transporter (TIGR02204) & EJJ066683.1 \\
\hline PvbC & Desaturase (TIGR02734) & EJJ06682.1 \\
\hline PvbM & Methyltransferase (PF13649) & EJJ06681.1 \\
\hline PvbK & Helix-turn-helix (PF13518) & EJJ06680.1 \\
\hline PvbE & LinE & EJJ06679.1 \\
\hline PvbL & LinL & EJJ06678.1 \\
\hline PvbG & LinG & EJJ06677.1 \\
\hline
\end{tabular}




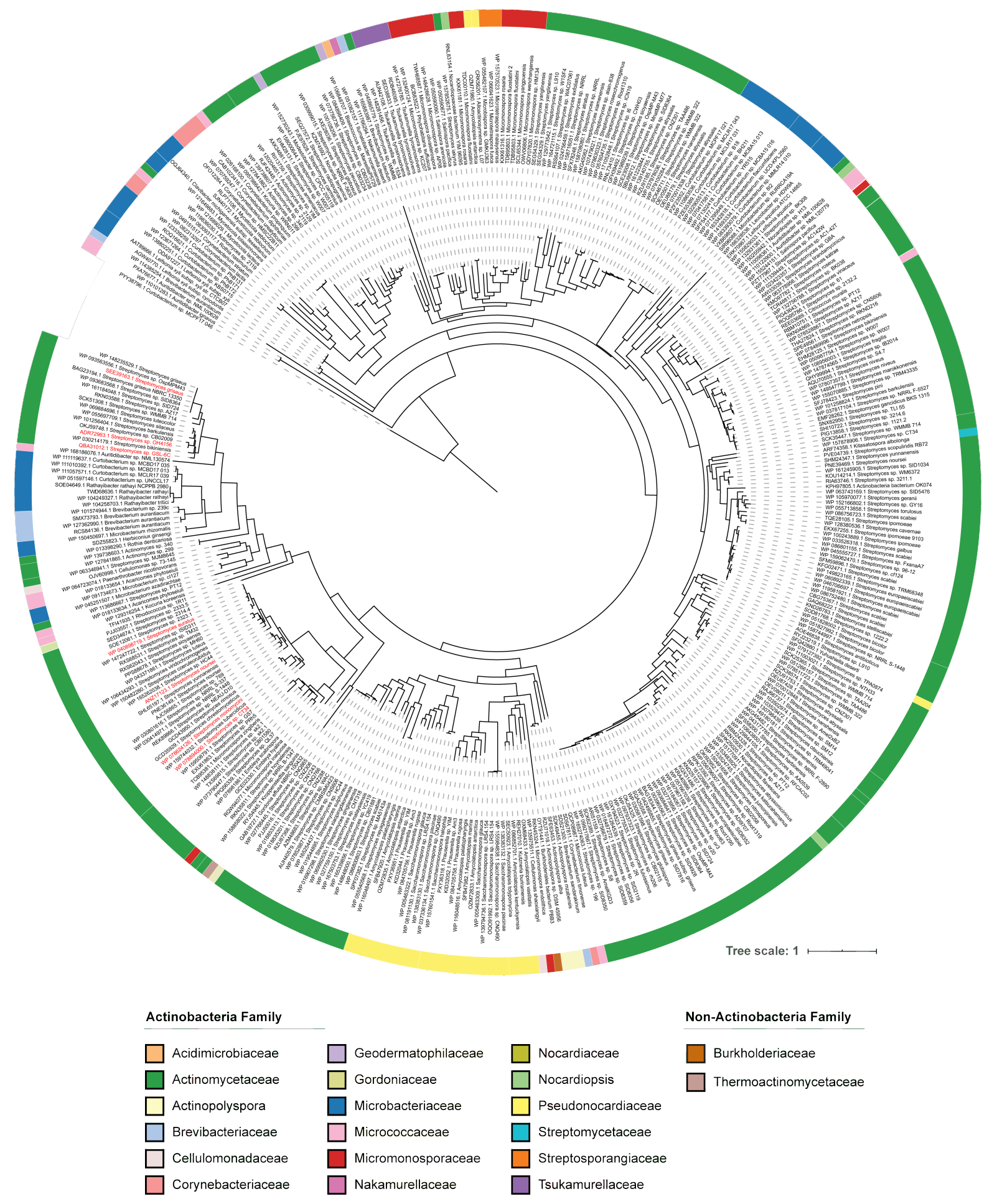

Figure S1: Phylogenetic distribution of LinE protein domains. Maximum likelihood tree of unique LinE sequences ( $n=382 ; 100 \%$ identical sequences have been removed) colored by taxonomic family. Known linaridin producers are colored in red. The tree was rooted using a predicted SdpB homolog (PYY38796.1) ${ }^{15}$ and visualized using interactive Tree of Life (iTOL). The phylogenetic classification of each identified LinE enzyme is listed in Supplemental Dataset 2. The data to regenerate this tree are available in phyloXML format (Supplemental Dataset 5). 


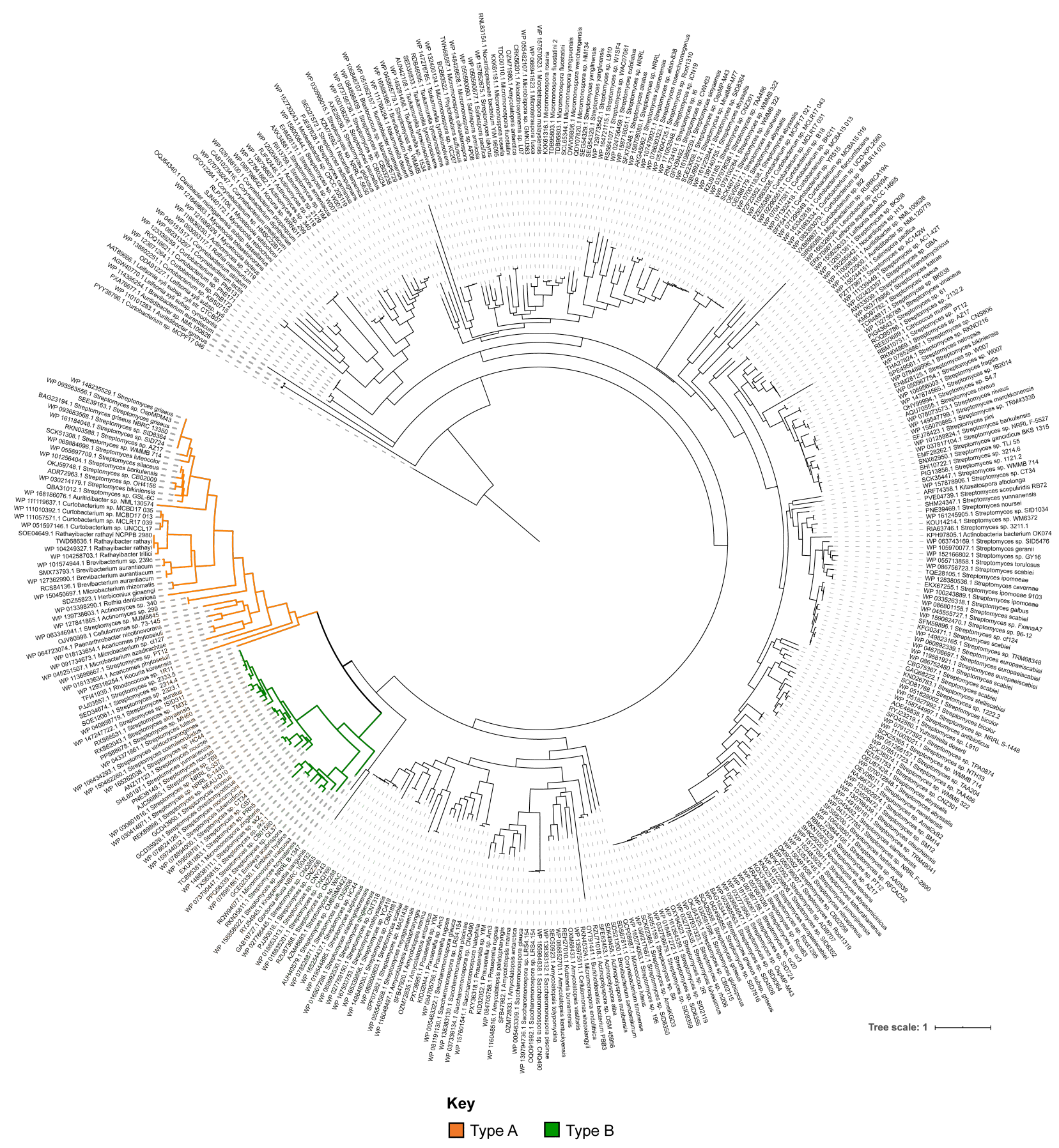

Figure S2. Phylogenetic relation of LinE proteins to known members. Maximum likelihood tree of unique LinE sequences ( $n=382 ; 100 \%$ identical sequences have been removed). LinE domains were obtained using an alignment to the custom LinE pHMM. The tree is identical to that shown in Figure S1; however, rather than showing taxonomy, the clades containing type A and type $B$ linaridins are highlighted orange and green, respectively. ${ }^{15}$ 
Note S1: Parsing script for pHMM-based sequence excision. The Python script, hmmexcise.py, takes a pHMM and a FASTA file as input. The input pHMM file must be pressed by hmmpress before use. The script then performs an hmmscan and prints a FASTA file with excised domains homologous to the pHMM. An optional bitscore '-bs' flag is provided to specify alternate inclusion thresholds (the default bitscore is 25.0)

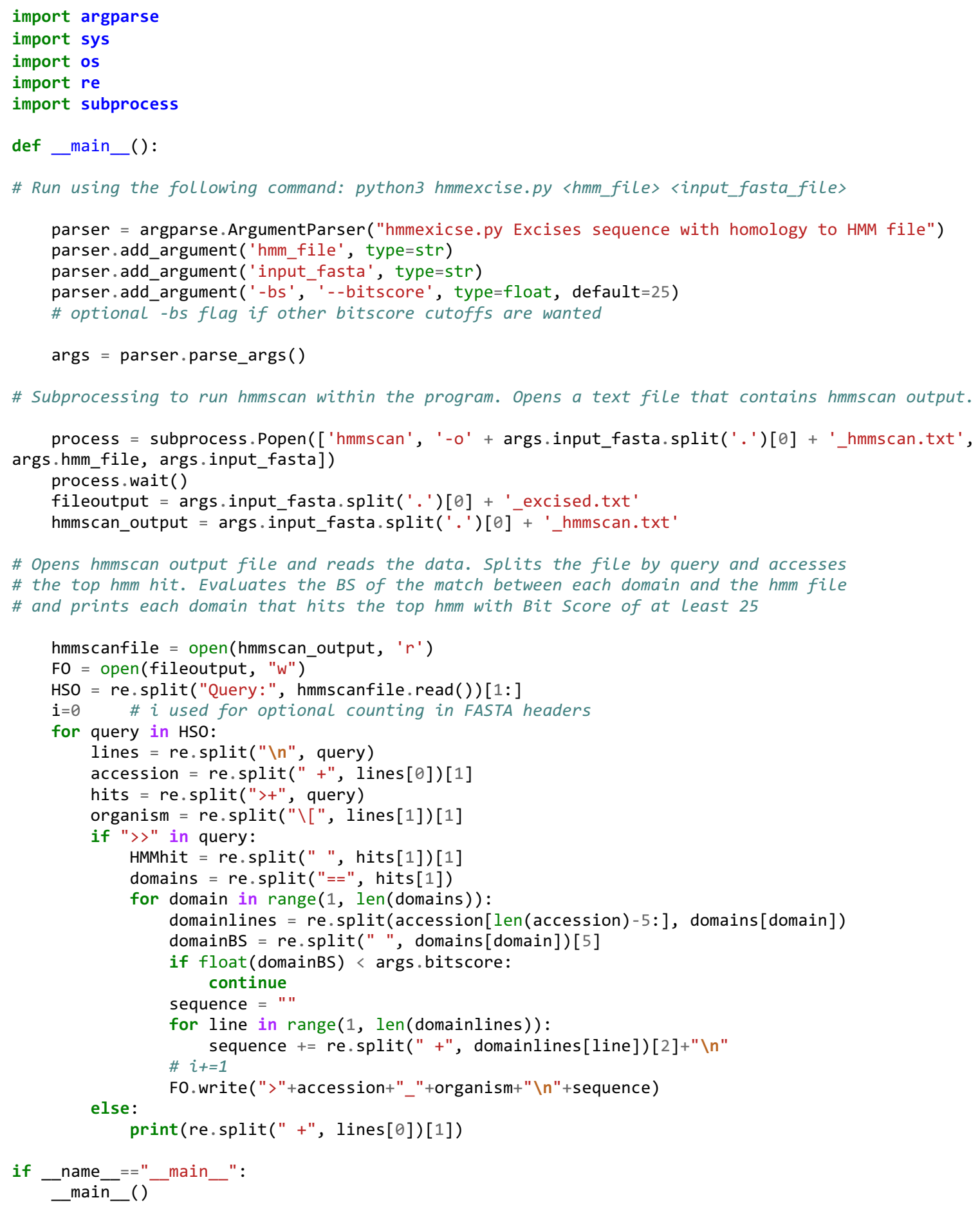


Table S2: Features and weights used in the RODEO linaridin module scoring. Heuristics analyzing hydrophobicity in the core region also include Thr because of the anticipated formation of Dhb.

\begin{tabular}{|c|c|c|}
\hline & Feature & Weight \\
\hline \multirow{33}{*}{ 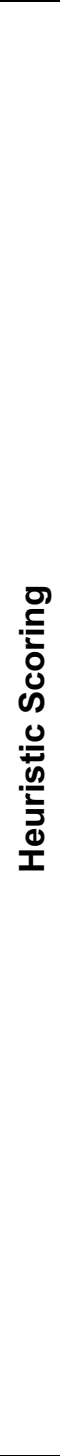 } & ABC transporter (PF00005 or PF02163 or PF00664) present in BGC & +1 \\
\hline & $\begin{array}{l}\text { Methyltransferase (PF08241 or PF08242 or PF13489 or PF13649 or PF13847) } \\
\text { present in BGC }\end{array}$ & +1 \\
\hline & Flavin decarboxylase (TIGR00521 or TIGR02113 or PF02441) present in BGC & +1 \\
\hline & $\begin{array}{l}\text { CXXC sequence motif present in core region with flavin decarboxylase present in } \\
\text { BGC }\end{array}$ & +1 \\
\hline & GST sequence motif present in leader with flavin decarboxylase present in BGC & +1 \\
\hline & LinE homolog present in BGC & +2 \\
\hline & Precursor is $<300$ nucleotides of a LinE, LinL, LinG, or LinH homolog & +1 \\
\hline & Precursor is $<600$ nucleotides of a LinE, LinL, LinG, or LinH homolog & +1 \\
\hline & Precursor is $>2200$ nucleotides from a LinE, LinL, LinG, or LinH homolog & -1 \\
\hline & Precursor length between 50 and 70 amino acids (inclusive) & +2 \\
\hline & Precursor length between 71 and 100 amino acids (inclusive) & +1 \\
\hline & Precursor length between 120 and 150 amino acids (inclusive) & -5 \\
\hline & Precursor length $>150$ amino acids & -10 \\
\hline & Leader region isoelectric point at $\mathrm{pH} 7<+1$ & +1 \\
\hline & Core region isoelectric point at $\mathrm{pH} 7>+6$ or $<-6$ & -1 \\
\hline & Core region contains $>15 \%$ Ala & +1 \\
\hline & Core region contains $>20 \%$ Ala & +1 \\
\hline & Core region contains $>10 \% \mathrm{Thr}$ & +1 \\
\hline & Core region contains $>15 \% \mathrm{Thr}$ & +1 \\
\hline & Core region contains $0 \mathrm{Thr}$ & -2 \\
\hline & Core region contains $>7 \%$ Val & +1 \\
\hline & Core region contains $>12 \% \mathrm{Val}$ & +1 \\
\hline & Core region contains $>2$ Cys & -1 \\
\hline & Core region contains 0 Cys & +1 \\
\hline & Core region contains $<50 \%$ hydrophobic residues $(G, A, V, L, M, I, T)$ & -1 \\
\hline & Core region contains $>60 \%$ hydrophobic residues $(G, A, V, L, M, I, T)$ & +1 \\
\hline & Core region contains $>75 \%$ hydrophobic residues $(\mathrm{G}, \mathrm{A}, \mathrm{V}, \mathrm{L}, \mathrm{M}, \mathrm{I}, \mathrm{T})$ & +1 \\
\hline & Core region begins with XTP sequence motif & +1 \\
\hline & Leader region contains GxG motif & +1 \\
\hline & Leader region contains LxD motif & +1 \\
\hline & Leader region contains FAN motif & +1 \\
\hline & Peptide contains any MEME/FIMO identified sequence motifs & +2 \\
\hline & Peptide contains no MEME/FIMO identified sequence motifs & -1 \\
\hline$\sum_{\substack{\boldsymbol{T} \\
\mathbf{I}}}^{\Sigma}$ & Peptide has homology to LinA custom HMM at e-value $<0.001$ & +10 \\
\hline$\sum_{\substack{++}}$ & SVM classifies as valid & +10 \\
\hline
\end{tabular}




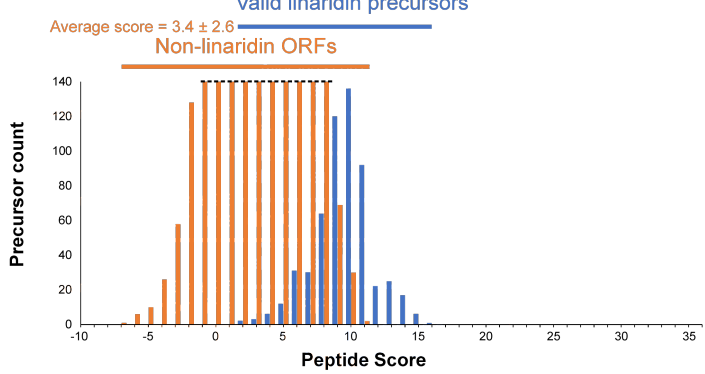

B
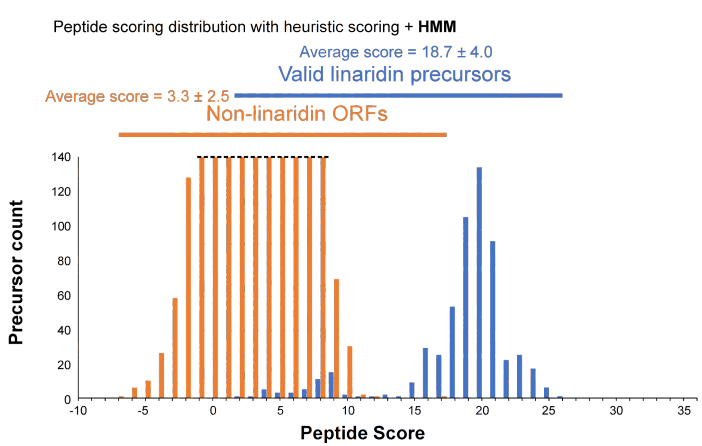

C
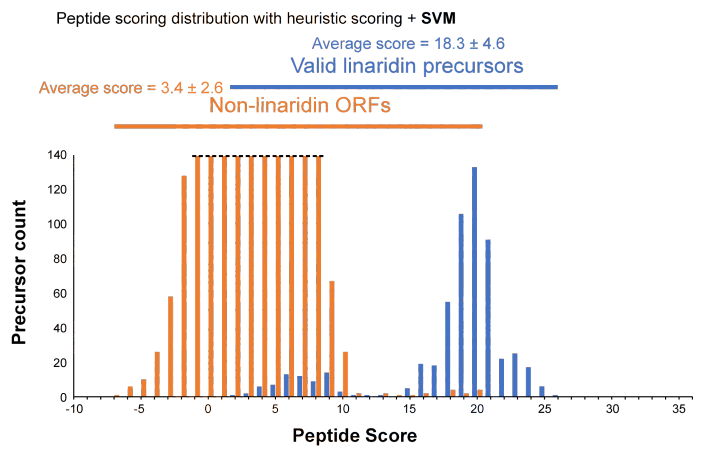

D
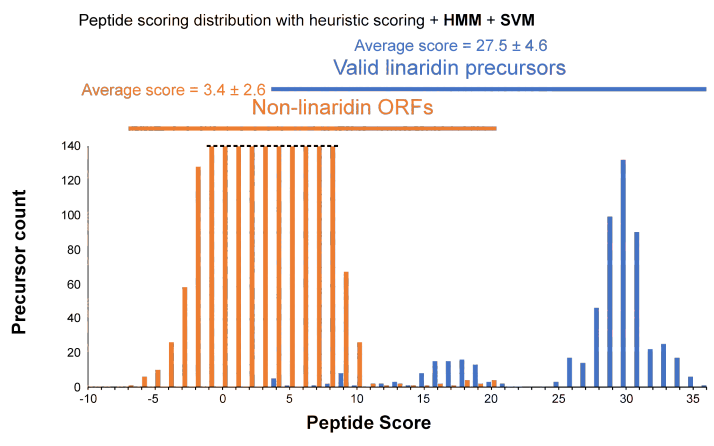

Figure S3: Precursor peptide scoring distributions. Precursor peptide score distributions are shown for the finalized linaridin dataset. (A) Score distribution using heuristics only (including MEME/FIMO-identified motif scoring). (B) Score distribution when distribution in Panel A was supplemented with support vector machine (SVM) learning classification. (C) Score distribution is shown when distribution in Panel A was supplemented with the LinA custom pHMM homology metric. (D) Score distribution when the distribution in Panel A was supplemented with SVM classification and the LinA pHMM homology metric simultaneously. 


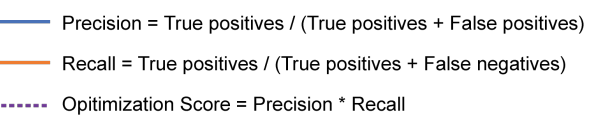

A

Metrics using heuristic scoring

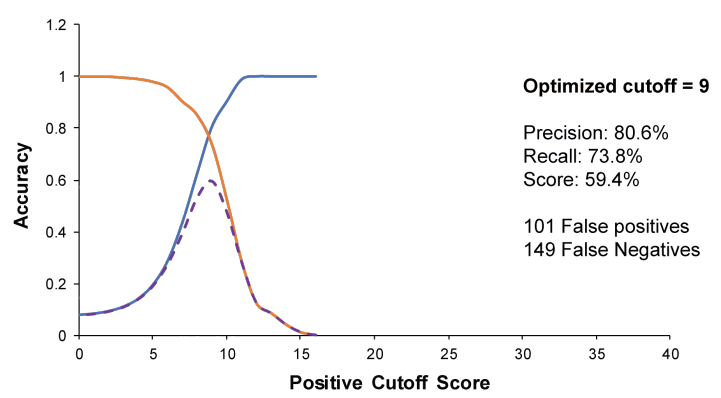

C

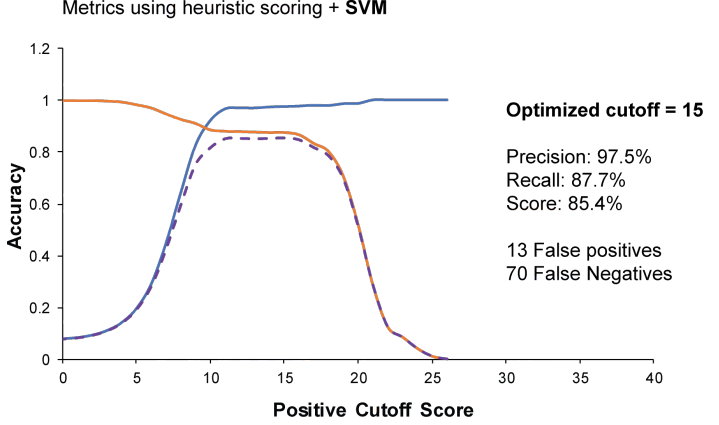

B

Metrics using heuristic scoring + HMM

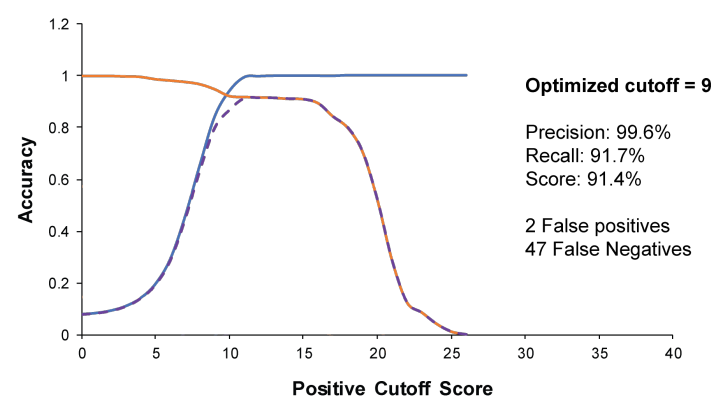

D Metrics using heuristic scoring + HMM + SVM

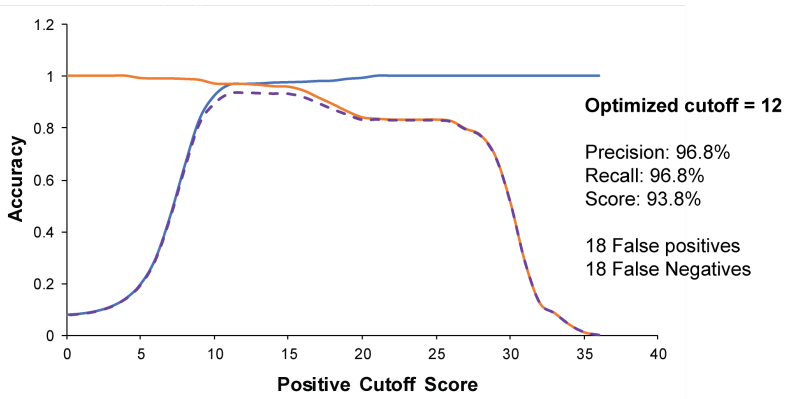

Figure S4: Evaluation of precision and recall for linaridin scoring. Precision and recall statistics are shown for four scoring procedures used to separate identified linaridin precursor peptides from hypothetical, non-coding sequences. The optimization score describes how a given scoring cutoff minimizes false-negative and false-positive classifications. (A) Metrics using only heuristic scoring. (B) Metrics using HMM homology and heuristic scoring. (C) Parameters using support vector machine (SVM) classification and heuristic scoring. (D) Metrics using SVM classification, HMM homology, and heuristic scoring. 
Table S3: Comparison of RODEO scoring to linaridins identified from other bioinformatic studies. Published datasets of other RiPP discovery tools were assessed for predicted linaridins. These were cross-referenced with the RODEO dataset generated during the current study. If common to both datasets, the average RODEO score is reported. Datasets with $<90 \%$ confirmed by RODEO include a number of predicted false-positives, which is further addressed in the main text. Supplemental Dataset $\mathbf{4}$ contains a full listing of previous bioinformatically identified linaridins.

\begin{tabular}{|c|c|c|c|c|c|}
\hline $\begin{array}{c}\text { RiPP Mining Tool } \\
\text { (publication } \\
\text { year) }\end{array}$ & $\begin{array}{c}\text { Dataset } \\
\text { Compilation and } \\
\text { Testing Methods }\end{array}$ & $\begin{array}{c}\text { Precursor } \\
\text { peptides } \\
\text { identified }\end{array}$ & $\begin{array}{c}\text { Confirmed by } \\
\text { RODEO (\%) }\end{array}$ & $\begin{array}{c}\text { Average RODEO } \\
\text { score of predicted } \\
\text { precursors }\end{array}$ & $\begin{array}{c}\text { Range of } \\
\text { RODEO scores } \\
\text { of predicted } \\
\text { precursors }\end{array}$ \\
\hline $\begin{array}{c}\text { Ma and Zhang } \\
(2020)^{15}\end{array}$ & $\begin{array}{c}\text { PSI-BLAST for } \\
\text { LinL homologs, } \\
\text { manual curation }\end{array}$ & 303 & $294(97 \%)$ & 29.5 & $14-36$ \\
\hline NeuRiPP (2019) 21 & $\begin{array}{c}\text { antiSMASH data, } \\
\text { class-independent } \\
\text { neural network }\end{array}$ & 34 & $32(94 \%)$ & 31.8 & $29-35$ \\
\hline $\begin{array}{c}\text { DeepRiPP } \\
(2020)^{22}\end{array}$ & $\begin{array}{c}\text { Whole genomes, } \\
\text { class-independent } \\
\text { neural network }\end{array}$ & 135 & $76(56 \%)$ & 31.2 & $17-36$ \\
\hline $\begin{array}{c}\text { MetaMiner } \\
(2019)^{23}\end{array}$ & $\begin{array}{c}\text { Paired genome } \\
\text { context and } \\
\text { tandem mass data }\end{array}$ & 1 & $1(100 \%)$ & 34 & 34 \\
\hline $\begin{array}{c}\text { RiPPMiner } \\
(2020)^{24}\end{array}$ & $\begin{array}{c}\text { Select genome } \\
\text { input, } \\
\text { multi-class SVM }\end{array}$ & 13 & $4(31 \%)$ & 30.5 & $12-36$ \\
\hline Current work & $\begin{array}{c}\text { PSI-BLAST for } \\
\text { LinE homologs, } \\
\text { heuristics + SVM }\end{array}$ & 568 & $100 \%$ & 27.8 & 30 \\
\hline
\end{tabular}




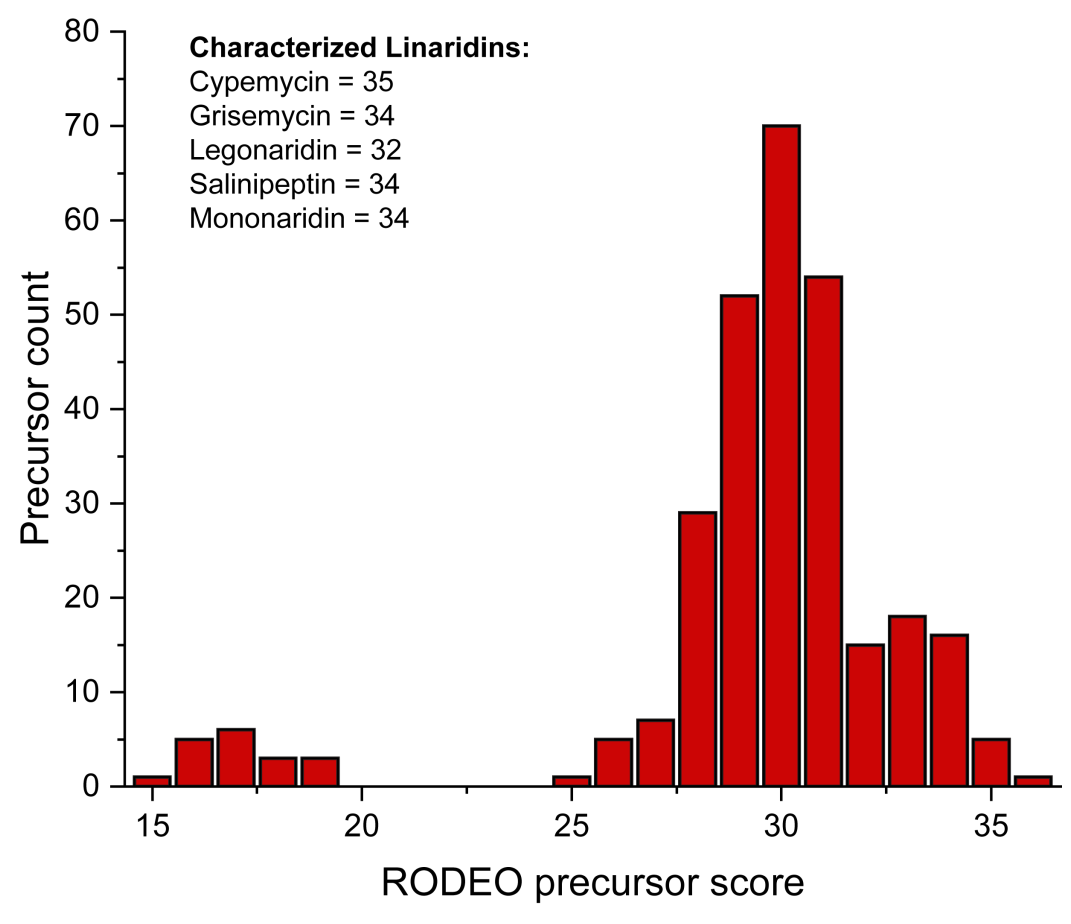

Figure S5: RODEO scoring of previously predicted linaridin precursor peptides. Histogram showing the score of predicted precursors from Ma and Zhang 2020 dataset, ${ }^{15}$ using the linaridin scoring module. The score of known precursor peptides, which were used in the training set, are shown in the top left. 
Table S4: Co-occurring genes that appear in linaridin BGCs. The most abundant genes appearing in linaridin BGCs are listed in descending order. Percent co-occurrence indicates the relative frequency a protein sequence within the BGC matches a pHMM. Eight genes were considered in both directions from the query; only the best scoring (lowest e-value) pHMM was included. Proteins were compared against PFAM, TIGRFAM, and custom pHMMs (noted in red). Custom pHMMs are available in Supplemental Dataset 1 as well as the RODEO webtool (http://ripp.rodeo) and RODEO Github (https://github.com/the-mitchell-lab/rodeo2). Cooccurrence statistics were obtained from the RODEO-derived dataset. Not all co-occurring protein families are necessarily involved in linaridin biosynthesis. However, some lower co-occurring entries, such as the decarboxylase (TIGR00521, yellow highlight), are associated with linaridin biosynthesis (AviCys formation) ${ }^{25}$ Overlap between LinH and LinE/G pHMMs is observed in some cases. Additionally, some BGCs contain more than one predicted linaridin precursor, further increasing percent co-occurence.

\begin{tabular}{|c|c|c|c|c|}
\hline pHMM ID & pHMM Name & pHMM Description & Count & $\%$ co-occurrence \\
\hline LinA & LinA & LinA (linaridin precursor) & 522 & $136 \%$ \\
\hline LinL & LinL & LinL Homolog & 386 & $101 \%$ \\
\hline LinH & LinH & LinH (Fusion of LinE/LinG) & 292 & $76 \%$ \\
\hline PF13649 & Methyltransf_25 & Methyltransferase domain (LinM homolog) & 268 & $70 \%$ \\
\hline TIGR02204 & TIGR02204 & MsbA_rel: ABC transporter, permease/ATP-binding protein & 206 & $54 \%$ \\
\hline LinE & LinE & LinE Homolog & 158 & $41 \%$ \\
\hline TIGR02734 & TIGR02734 & crtl_fam: phytoene desaturase & 154 & $40 \%$ \\
\hline LinG & LinG & LinG Homolog & 113 & $30 \%$ \\
\hline PF00196 & GerE & Bacterial regulatory proteins, luxR family & 87 & $23 \%$ \\
\hline PF00072 & Response_reg & Response regulator receiver domain & 68 & $18 \%$ \\
\hline TIGR01188 & TIGR01188 & $\begin{array}{l}\text { drrA: daunorubicin resistance } A B C \text { transporter, ATP-binding } \\
\text { protein }\end{array}$ & 62 & $16 \%$ \\
\hline PF07730 & HisKA_3 & Histidine kinase & 59 & $15 \%$ \\
\hline PF01061 & ABC2_membrane & ABC-2 type transporter & 50 & $13 \%$ \\
\hline PF01551 & Peptidase_M23 & Peptidase family M23 & 37 & $10 \%$ \\
\hline TIGR00521 & TIGR00521 & $\begin{array}{l}\text { coaBC_dfp: phosphopantothenoylcysteine decarboxylase / } \\
\text { phosphopantothenate--cysteine ligase }\end{array}$ & 36 & $9 \%$ \\
\hline PF03704 & BTAD & Bacterial transcriptional activator domain & 33 & $9 \%$ \\
\hline PF12698 & ABC2_membrane_3 & ABC-2 family transporter protein & 31 & $8 \%$ \\
\hline PF12840 & HTH_20 & Helix-turn-helix domain & 30 & $8 \%$ \\
\hline PF09335 & SNARE_assoc & SNARE associated Golgi protein & 29 & $8 \%$ \\
\hline PF04134 & DUF393 & Protein of unknown function, DUF393 & 28 & $7 \%$ \\
\hline PF06738 & ThrE & Putative threonine/serine exporter & 27 & $7 \%$ \\
\hline PF00719 & Pyrophosphatase & Inorganic pyrophosphatase & 25 & $7 \%$ \\
\hline PF12680 & SnoaL_2 & SnoaL-like domain & 25 & $7 \%$ \\
\hline PF02113 & Peptidase_S13 & D-Ala-D-Ala carboxypeptidase 3 (S13) family & 23 & $6 \%$ \\
\hline PF05719 & GPP34 & Golgi phosphoprotein 3 (GPP34) & 23 & $6 \%$ \\
\hline PF00583 & Acetyltransf_1 & Acetyltransferase (GNAT) family & 21 & $5 \%$ \\
\hline TIGR02857 & TIGR02857 $^{-}$ & CydD: thiol reductant $A B C$ exporter, CydD subunit & 21 & $5 \%$ \\
\hline PF13560 & HTH_31 & Helix-turn-helix domain & 21 & $5 \%$ \\
\hline TIGR02203 & TIGR02203 & MsbA_lipidA: lipid A export permease/ATP-binding protein MsbA & 21 & $5 \%$ \\
\hline TIGR03883 & TIGR03883 & $\begin{array}{l}\text { DUF2342_F420: uncharacterized protein, coenzyme F420 } \\
\text { biosynthesis associated }\end{array}$ & 20 & $5 \%$ \\
\hline PF01906 & YbjQ_1 & Putative heavy-metal-binding & 20 & $5 \%$ \\
\hline TIGR01189 & TIGR01189 & ccmA: heme ABC exporter, ATP-binding protein CcmA & 20 & $5 \%$ \\
\hline
\end{tabular}


Table S5: Identity of first amino acid in core region. The amino acid identity at position +1 of the core region of predicted linaridins is given as a function of whether the BGC encodes or omits a a linaridin methyltransferase (LinM) homolog. The last column indicates the expected frequency for each amino acid based on codon usage in Streptomyces sp. where the majority of linaridins are encoded. Values underlined in red text indicate a significant enrichment after factoring in codon usage frequency. No naturally occurring linaridins were found with residue +1 being Asp, Glu, Lys, Asn, Pro, Arg, Trp, or Tyr.

\begin{tabular}{|c|c|c|c|c|c|}
\cline { 2 - 6 } \multicolumn{1}{c|}{} & \multicolumn{2}{c|}{ LinM Present } & \multicolumn{2}{c|}{ LinM Absent } & $\begin{array}{c}\text { Expected Frequency in } \\
\text { Streptomyces sp. }\end{array}$ \\
\hline Position +1 & \# Cores & $\%$ & \# Cores & $\%$ & $\%$ \\
\hline A & 345 & $\underline{\mathbf{7 2 . 9}}$ & 29 & $\underline{\mathbf{3 0 . 5}}$ & 13.7 \\
\hline C & 1 & 0.2 & 15 & $\mathbf{1 5 . 8}$ & 0.8 \\
\hline D & 0 & 0 & 0 & 0 & 5.9 \\
\hline E & 0 & 0 & 0 & 0 & 5.7 \\
\hline F & 22 & 4.7 & 1 & 1.1 & 2.7 \\
\hline G & 44 & 9.3 & 2 & 2.1 & 9.6 \\
\hline H & 1 & 0.2 & 0 & 0 & 2.3 \\
\hline I & 5 & 1.1 & 1 & 1.1 & 3 \\
\hline K & 0 & 0 & 0 & 0 & 2.1 \\
\hline L & 22 & 4.7 & 3 & 3.2 & 10.3 \\
\hline M & 6 & 1.3 & 0 & 0 & 1.6 \\
\hline N & 0 & 0 & 0 & 0 & 1.7 \\
\hline P & 0 & 0 & 0 & 0 & 6.3 \\
\hline Q & 0 & 0 & 1 & 1.1 & 2.7 \\
\hline R & 0 & 0 & 0 & 0 & 8.3 \\
\hline S & 15 & 3.2 & 3 & 3.2 & 5.1 \\
\hline T & 5 & 1.1 & 38 & 40.0 & 6.1 \\
\hline V & 7 & 1.5 & 2 & 2.1 & 8.4 \\
\hline W & 0 & 0 & 0 & 0 & 2.5 \\
\hline Y & 0 & 0 & 0 & 0 & $\mathbf{1 0 0}$ \\
\hline Total & $\mathbf{4 7 3}$ & $\mathbf{1 0 0}$ & $\mathbf{9 5}$ & $\mathbf{1 0 0}$ & \\
\hline & & & & & \\
\hline
\end{tabular}




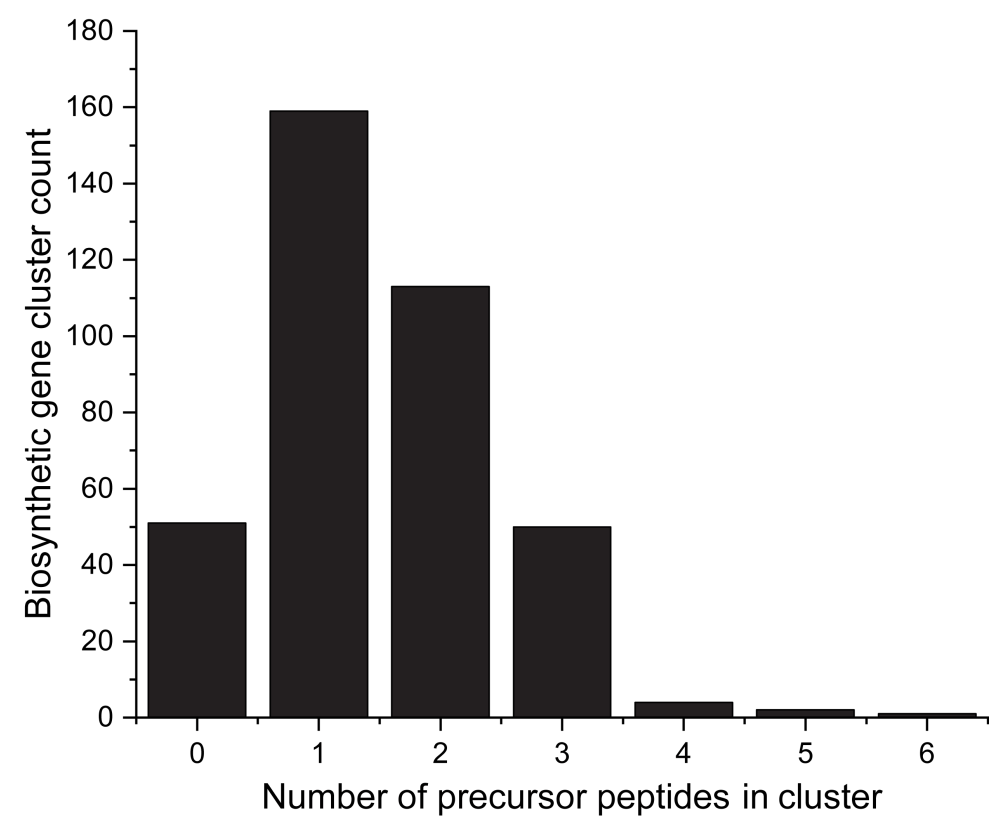

Figure S6: Number of precursors per BGC. Histogram of the number of linaridin precursor peptides detected within each non-redundant BGC $(n=382)$. Precursor peptides were identified by RODEO and deemed valid if receiving a score $\geq 12$. 

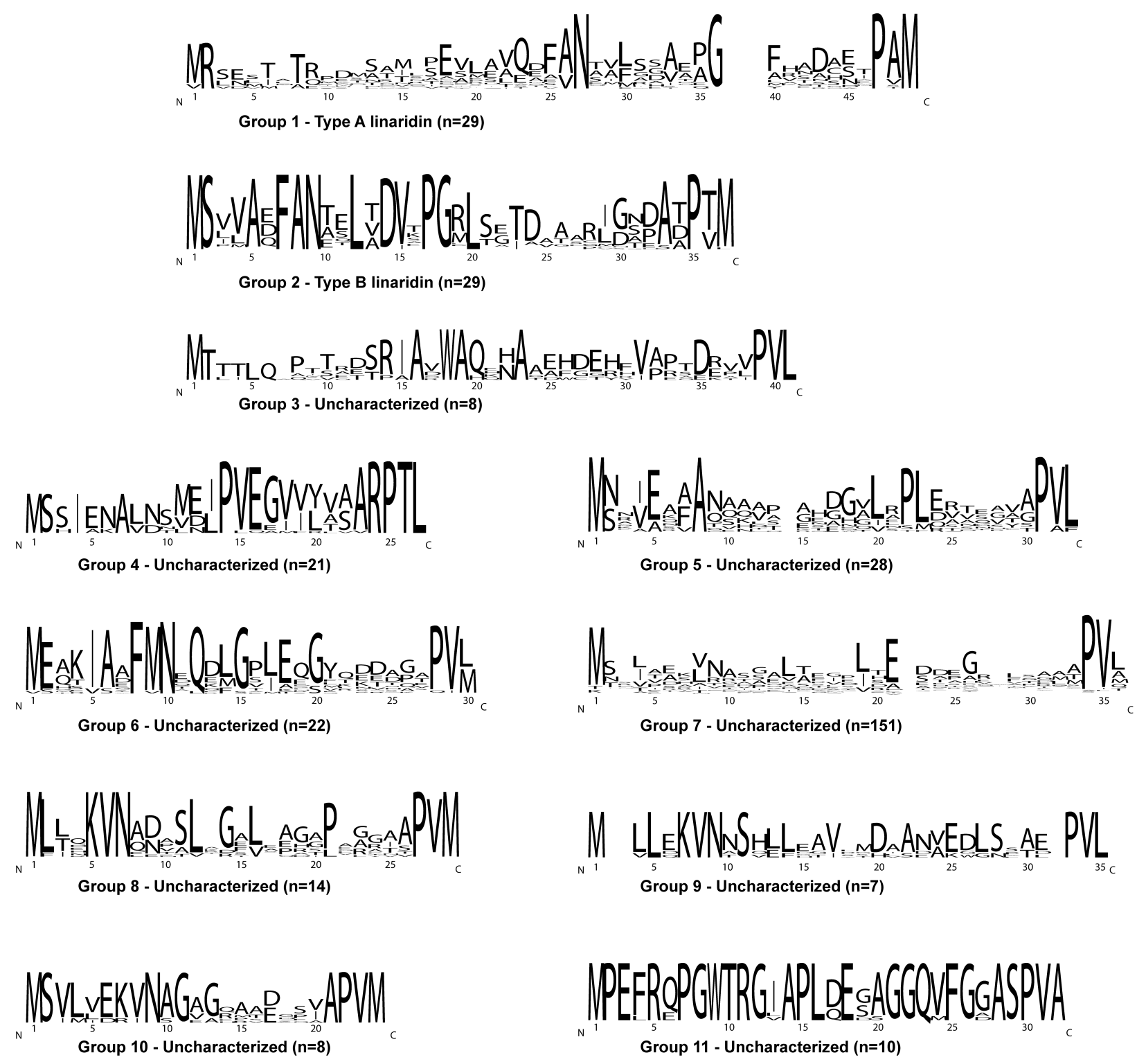

Figure S7: Sequence analysis of RODEO-identified linaridin leader region. All groups within the SSN containing greater than four members (Figure 2) were analyzed for leader sequence content using WebLogo. ${ }^{26}$ Groups that include a known members are denoted with their type; all others are classified as "Uncharacterized". 

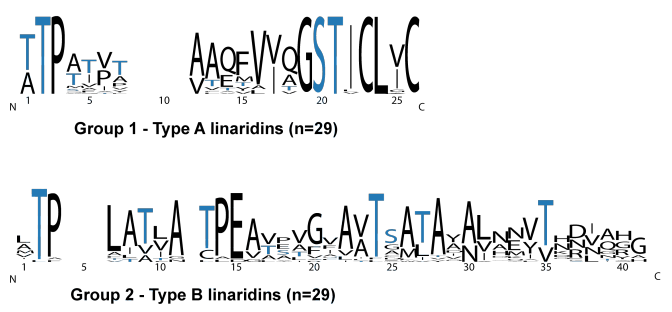

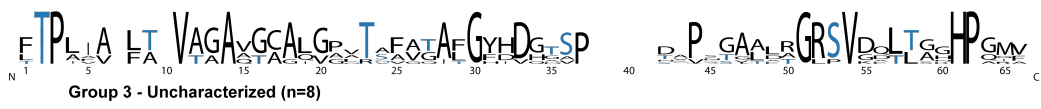
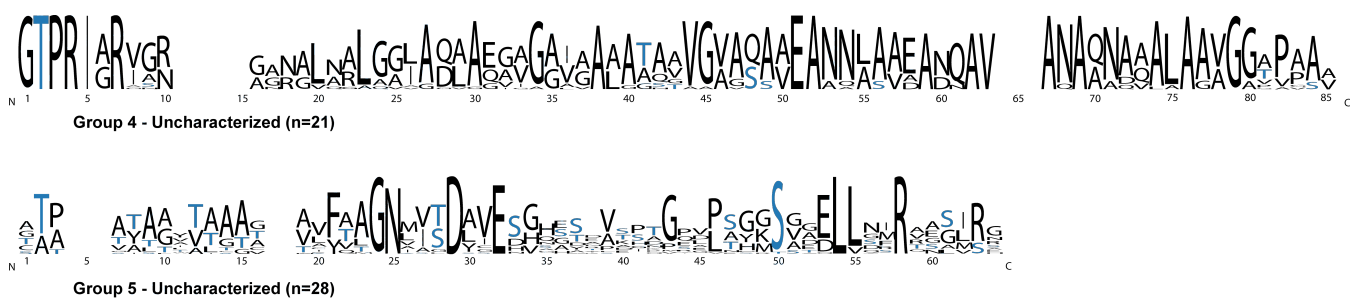

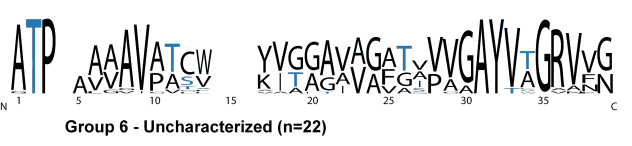

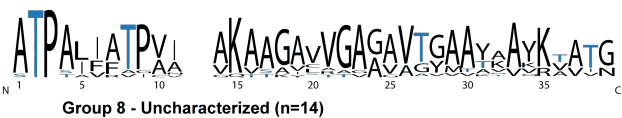

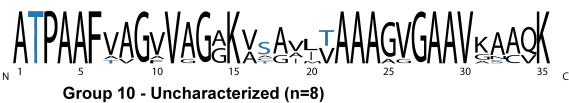

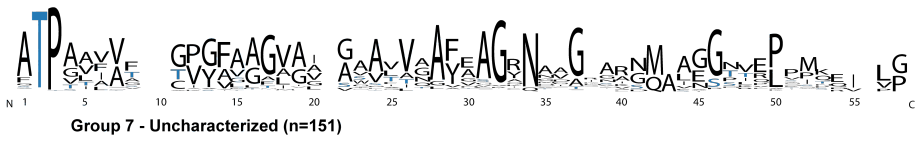

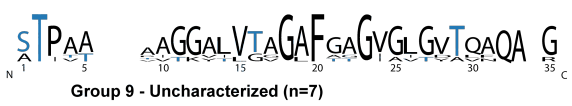

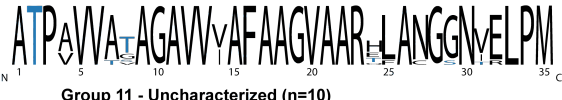

Figure S8: Sequence analysis of RODEO identified linaridin core region. All groups containing greater than four members on the SSN (Figure 2) were analyzed for core sequence content using WebLogo. ${ }^{26}$ Groups that include a known members are denoted with their type, with all other clusters classified as "Uncharacterized". Blue, Ser and Thr (potential dehydration sites). 


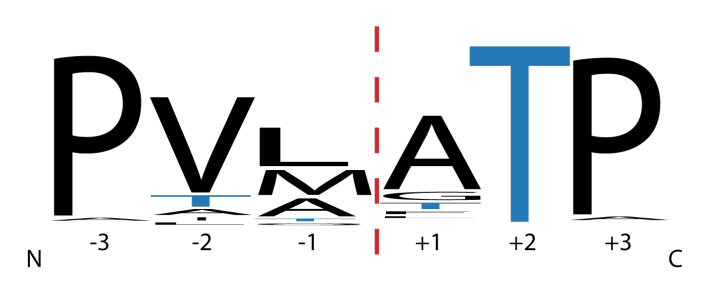

Figure S9: Sequence analysis of linaridin leader/core proteolytic site. A Logo of all predicted precursor proteolytic cleavage sites, manually curated to remove any potential misidentifications. A total of 549 predicted proteolytic sites were aligned using MAFFT ${ }^{4}$ with visualization using WebLogo. ${ }^{26}$ MAFFT website: https://mafft.cbrc.jp/alignment/server/ 


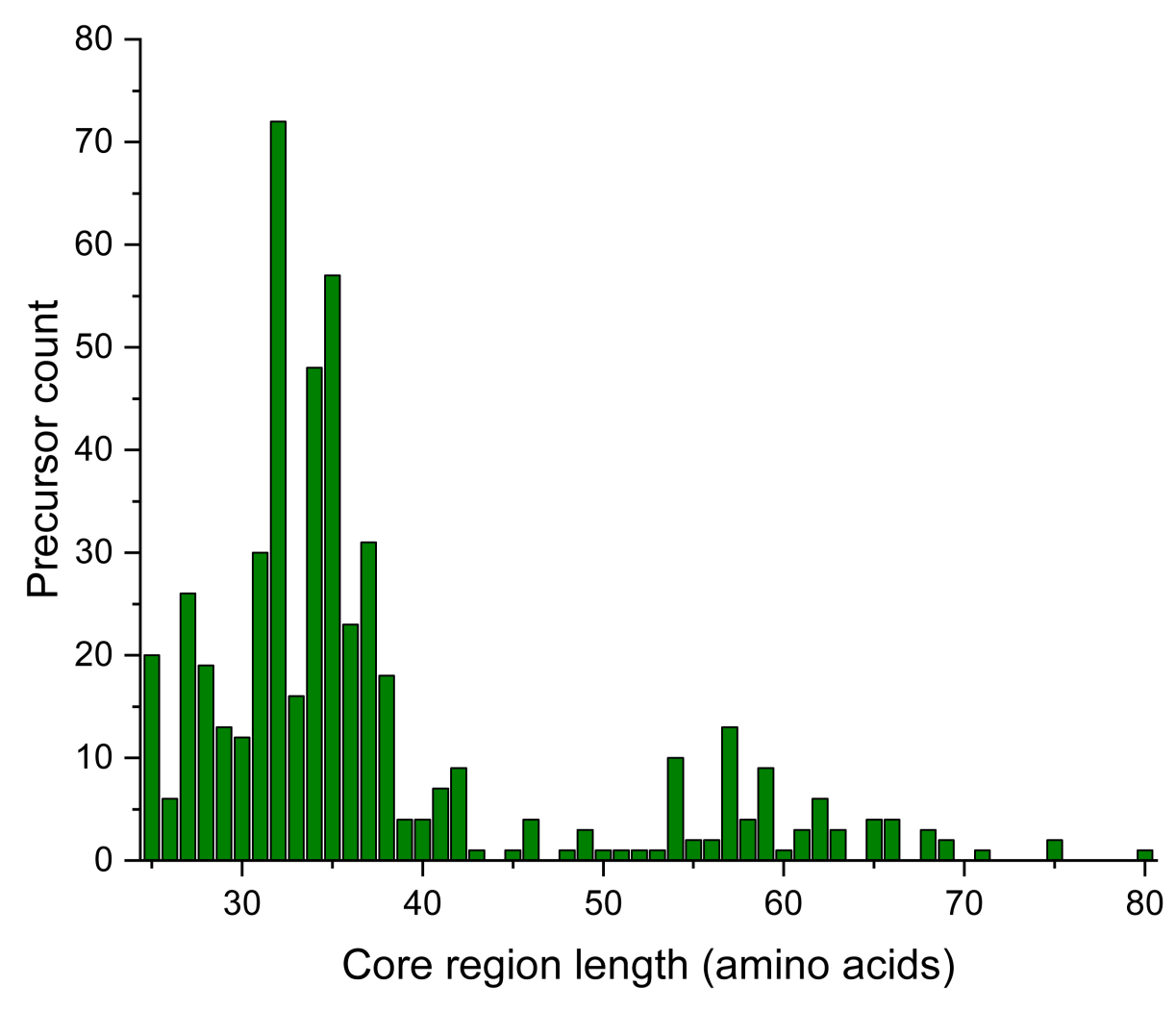

Figure S10: Linaridin core region length variability. Histogram of linaridin core region length identified by RODEO $(n=568)$. Sequences were identified/scored by RODEO. The populous group from 25-40 residues comprises all isolated linaridins, while a significant number of linaridins with longer core sequences remain uncharacterized. 

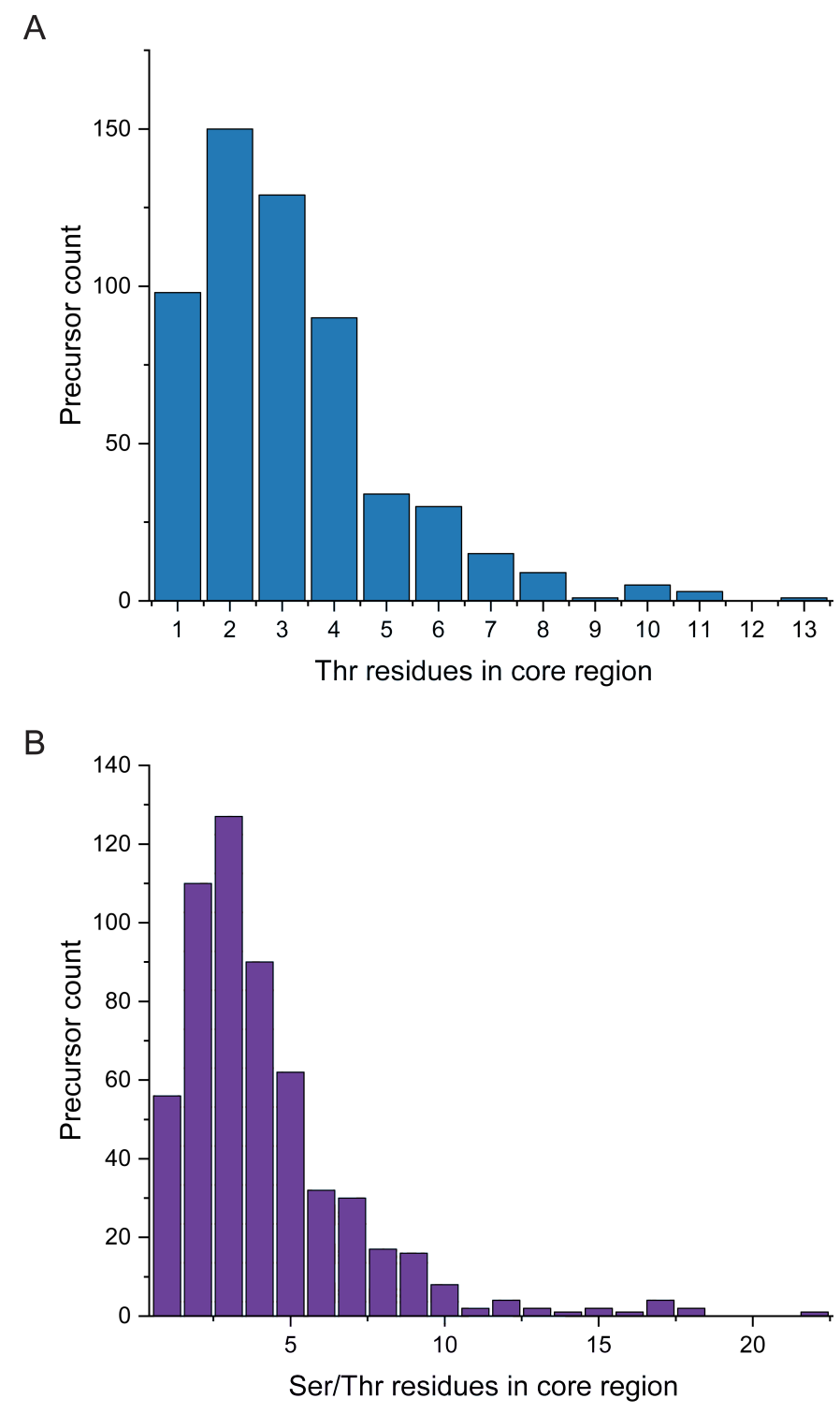

Figure S11: Thr and Ser content of predicted core region. Histogram showing the Thr content (A) and combined Ser/Thr content (B) of the linaridin core regions identified by RODEO ( $n=568)$. The predicted leader/core cleavage site was predicted by motif analysis (Figure S9). Characterized linaridins contain 2-7 Thr in the core regions with all being converted to Dhb. Dehydroalanine formation (from Ser) has not yet been observed in wild-type linaridins but remains theoretically possible. 
Streptomyces sp. NRRL F-2890

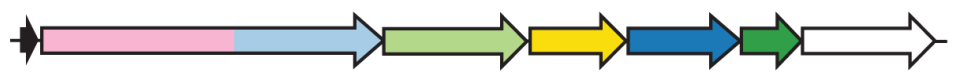

Streptomyces xiamensis

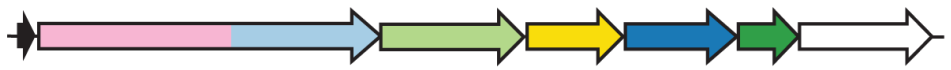

Streptomyces atratus

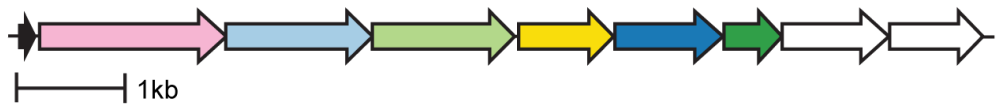

LinA (Precursor)

$\square$ LinL Protein

$\square$ LanB Glutamylation Domain

$\square$ LinE Protein

$\square$ LanC Cyclase

$\square$ Unknown Function

$\square$ LinG Protein

$\square$ LanB Elimination Domain

leader peptide

NRRL F-2890: $\overline{\text { MGADLITAAANEELSDLDLDLTFAPNDE }}$

S. xiamensis: MGADLITAAANEELSDLDLDLTFAPNDE

S. atratus: MSTDLLIAAADEELSDLDLDVHFMSSGD core peptide

NTHVMLACAVD SMGNNVNTSRGI I PQAPVCCA

NTHVMLACAVD SMGNNVNTSRGI I PQAPVCCA

VADQMYSCAVDSMGNGSSTSNGWRTCCA

Figure S12: Hybrid lanthipeptide and linaridin BGCs. Linaridin-lanthipeptide hybrids from various Streptomyces sp. The first two examples contain a fused LanB, whereas Streptomyces atratus contains a split LanB, like those found in thiopeptide biosynthetic gene clusters. ${ }^{27}$ The class I lanthipeptide RODEO module was used to identify precursor peptides and their respective proteolytic cleavage sites in combination with manual curation. 
A Kroppenstedtia sanguinis $\times 0209$

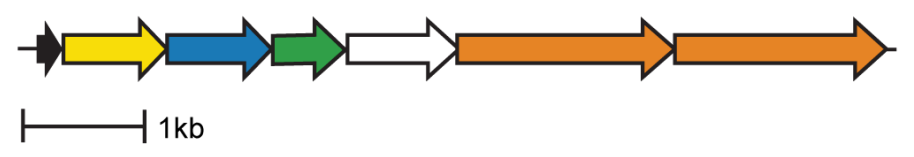

Precursor: MKMWEIEDQLNGRGHVTAASVGTGPLAAAVPQRTAMMS SLAQS SDVMT SLASVSASMAS I YALANSGHRP

B Burkholderiales bacterium PBB3

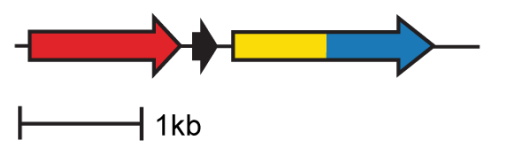

Precursor: MQI DVKI LDPRLTDQLPSY-ATPGSAGLDLRACLTEPLTLQPNAWQLVPTGMAIYLEDPAYAALILPRSGLGHKH GIVLGNLVGLIDSDYQGQLMVSAWNRSTTAFTIEPMERIAQLVIVPVVQAQFNVVSEFPASQRGEGGYGSTGKA
LinA (Precursor)
$\square$ LinL Protein
Unknown Function
$\square$ LinE Protein
$\square$ ABC Transporter
$\square$ LinG Protein
$\square$ LinD Protein

Figure S13: Non-Actinobacterial Linaridin BGCs. (A) BGC found in Kroppenstadia sanguinis X0209 (Firmicutes). The associated precursor peptide was not judged to be a valid linaridin precursor peptide by the RODEO module. (B) BGC found in Burkholderiales bacterium PBB3 (Proteobacteria). This cluster lacks a LinL homolog and contains an unusually long precursor peptide, scoring 12 on the linaridin module of RODEO. 


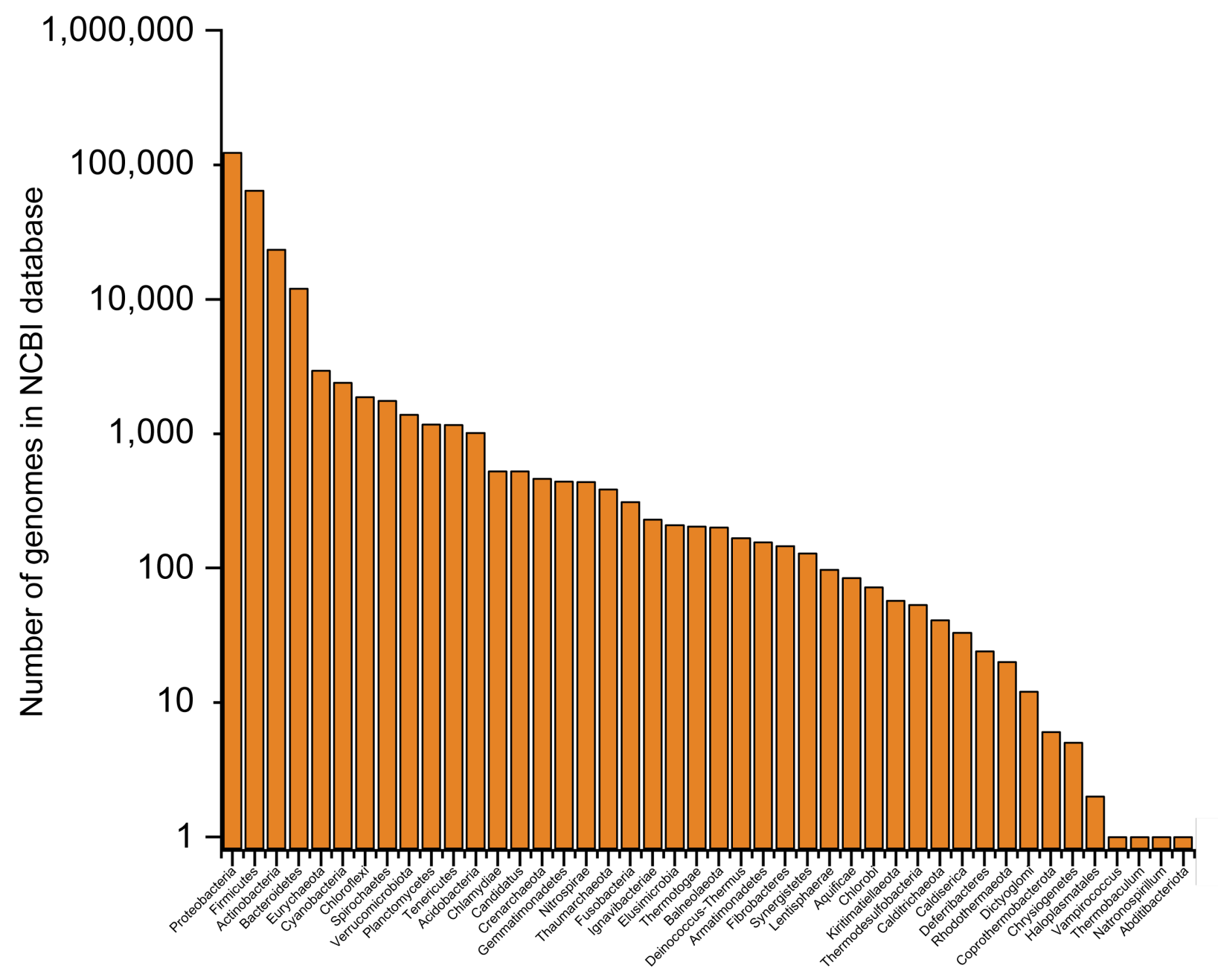

Figure S14: Phylogenetic distribution of NCBI sequences. Logarithmic histogram showing the number of sequenced prokaryotic genomes in NCBI database (Release 237) based on phylum. 


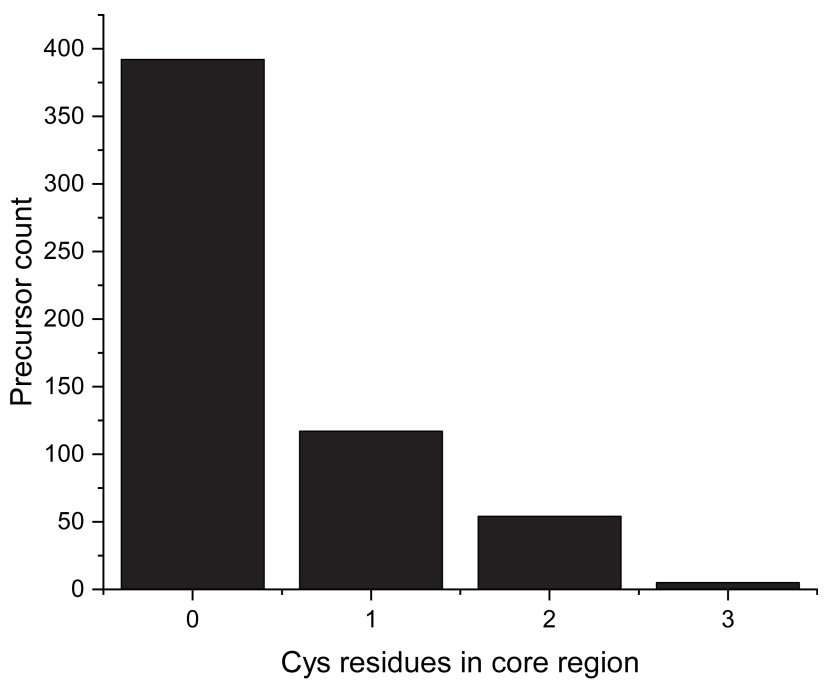

Figure S15: Cys content of core peptides predicted by RODEO. Histogram of linaridin core peptide Cys content $(n=568)$. Sequences were identified and scored by RODEO with the proteolytic sites predicted by motif analysis (Figure S9). Hybrid BGCs do not contain precursors validated by RODEO and are therefore not included in this analysis. Characterized linaridins contain either 0 or 2 Cys correlating with the presence of a gene encoding a decarboxylase (AviCys formation). 
Table S6: Linaridin core regions containing Cys. Below is a subset of linaridin core sequences containing Cys (red) but lacking a putative AviCys-forming decarboxylase. Saccharomonospora sp. contain Cys at the first position of the core region (+1) followed by a Thr/Ser-rich region (blue).

\begin{tabular}{|l|l|l|l|}
\hline Genus / species & Strain & NCBI Accession & Truncated core peptide (+1 to +26) \\
\hline Saccharomonospora sp. & LRS4.154 & OQO91990.1 & CTTSTTTATLAGTVGMVFTAGIISDA \\
Saccharomonospora sp. & CNQ490 & WP_024877745.1 & CTTTTTLTTTTATCTVFATGISSDAS \\
Saccharomonospora sp. & CNQ490 & WP_024877746.1 & CTTTTTTSTITGCVGTVFTMGVISDA \\
Saccharomonospora sp. & LRS4.154 & OQO91991.1 & CTATTLTTTTATCTVFATGIIGDAGE \\
Saccharomonospora piscinae & $06168 \mathrm{H}-1$ & WP_138383134.1 & CTATTLTTTTATCTVFATGSIGDAGE \\
Saccharomonospora piscinae & 06168H-1 & WP_081191125.1 & CTTSTTTATLAGTVGMVFTAGIISDA \\
\hline
\end{tabular}


Table S7: List of bacterial strains evaluated for linaridin production. The 34 strains listed below originated from the Agricultural Research Service Culture Collection (NRRL) in Peoria, IL (https://nrrl.ncaur.usda.gov/).

\begin{tabular}{|l|l|}
\hline Genus / species & Strain designation (NRRL) \\
\hline Streptomyces sp. & B-1347 \\
\hline Salinispora pacifica & B-24797 \\
\hline Streptomyces antibioticus & B-1701, B-2032, B-2770, B-8002 \\
\hline Streptomyces auratus & B-8097 \\
\hline Streptomyces bicolor & B-5348 \\
\hline Streptomyces bottropensis & ISP-5262 \\
\hline Streptomyces iakyrus & ISP-5482 \\
\hline Streptomyces monomycini & B-24309 \\
\hline Streptomyces neyagawaensis & B-3092, B-16496, ISP-5588 \\
\hline Streptomyces noursei & B-1714 \\
\hline Streptomyces scabrisporus & B-24202 \\
\hline Streptomyces scopuliridis & B-24574 \\
\hline Streptomyces sioyaensis & B-5408 \\
\hline Streptomyces sp. & F-5630 \\
\hline Streptomyces sp. & S-337 \\
\hline Streptomyces sp. & S-1448 \\
\hline Streptomyces stelliscabiei & B-24447 \\
\hline Streptomyces sulphureus & B-1331, B-2195 \\
\hline Streptomyces torulosus & S-189, F-3039, B-3889 \\
\hline Streptomyces viridochromogenes & B-3607, B-12033, S-256, S-452, S-453, S-635, S-636 \\
\hline
\end{tabular}


Table S8: Pegvadin A MS/MS ion assignments. Masses assigned with calculated (calc.) and observed (obsv.) values given along with the error (ppm values given) in the assignment. Fragments were observed in the 1+ charge state unless otherwise noted.

\begin{tabular}{|r|r|r|c|}
\hline lon & Calc. Mass & Obsv. Mass & Error \\
\hline $\mathrm{y} 3$ & 416.2616 & 416.2611 & 1.1 \\
\hline $\mathrm{y} 4$ & 531.2885 & 531.2879 & 1.1 \\
\hline $\mathrm{y} 5$ & 659.3835 & 659.3827 & 1.3 \\
\hline $\mathrm{y} 6$ & 742.4206 & 742.4196 & 1.4 \\
\hline $\mathrm{y} 7$ & 841.4890 & 841.4875 & 1.8 \\
\hline $\mathrm{y} 8$ & 970.5316 & 970.5301 & 1.6 \\
\hline $\mathrm{y} 9$ & 1107.5905 & 1107.5890 & 1.3 \\
\hline $\mathrm{y} 10$ & 1220.6746 & 1220.6726 & 1.7 \\
\hline $\mathrm{y} 11$ & 1291.7117 & 1291.7096 & 1.6 \\
\hline $\mathrm{y} 12$ & 1454.7750 & 1454.7728 & 1.5 \\
\hline $\mathrm{y} 13$ & 1525.8122 & 1525.8099 & 1.5 \\
\hline $\mathrm{y} 14$ & 1608.8493 & 1608.8463 & 1.9 \\
\hline $\mathrm{y} 15$ & 1679.8864 & 1679.8828 & 2.1 \\
\hline $\mathrm{y} 16$ & 1766.9184 & 1766.9136 & 2.7 \\
\hline $\mathrm{y} 17$ & 1849.9555 & 1849.9517 & 2.1 \\
\hline $\mathrm{y} 19^{2+}$ & 1010.5344 & 1010.5325 & 1.9 \\
\hline $\mathrm{y} 23^{2+}$ & 1201.6271 & 1201.6255 & 1.3 \\
\hline $\mathrm{y} 24^{2+}$ & 1243.1456 & 1243.1439 & 1.4 \\
\hline $\mathrm{y} 25^{2+}$ & 1278.6642 & 1278.6621 & 1.6 \\
\hline $\mathrm{y} 26^{2+}$ & 1335.2062 & 1335.2041 & 1.6 \\
\hline $\mathrm{y} 27^{2+}$ & 1376.7248 & 1376.7227 & 1.5 \\
\hline $\mathrm{y} 30^{2+}$ & 1517.3117 & 1517.3098 & 1.3 \\
\hline $\mathrm{y} 31^{2+}$ & 1558.8303 & 1558.8278 & 1.6 \\
\hline $\mathrm{b} 4$ & 435.2966 & 435.2961 & 1.1 \\
\hline $\mathrm{b} 5$ & 506.3337 & 506.3331 & 1.3 \\
\hline $\mathrm{b} 6$ & 589.3708 & 589.3700 & 1.3 \\
\hline $\mathrm{b} 7$ & 702.4549 & 702.4539 & 1.4 \\
\hline $\mathrm{b} 8$ & 773.4920 & 773.4909 & 1.5 \\
\hline $\mathrm{b} 9$ & 856.5291 & 856.5277 & 1.6 \\
\hline & & & \\
\hline
\end{tabular}


Table S9: Pegvadin B MS/MS ion assignments. Masses assigned with calculated (calc.) and observed (obsv.) values given along with the error (ppm values given) in the assignment. Fragments were observed in the $1+$ charge state unless otherwise noted.

\begin{tabular}{|c|r|r|c|}
\hline lon & Calc. Mass & Obsv. Mass & Error \\
\hline $\mathrm{y} 3$ & 416.2616 & 416.2611 & 1.2 \\
\hline $\mathrm{y} 4$ & 531.2885 & 531.2879 & 1.1 \\
\hline $\mathrm{y} 5$ & 659.3835 & 659.3825 & 1.5 \\
\hline $\mathrm{y} 6$ & 742.4206 & 742.4195 & 1.5 \\
\hline $\mathrm{y} 8$ & 970.5316 & 970.5299 & 1.8 \\
\hline $\mathrm{y} 9$ & 1107.5905 & 1107.5884 & 2.0 \\
\hline $\mathrm{y} 12^{2+}$ & 727.8914 & 727.8902 & 1.6 \\
\hline $\mathrm{y} 13^{2+}$ & 763.4100 & 763.4087 & 1.6 \\
\hline $\mathrm{y} 14^{2+}$ & 804.9285 & 804.9272 & 1.7 \\
\hline $\mathrm{y} 15^{2+}$ & 840.4471 & 840.4459 & 1.5 \\
\hline $\mathrm{y} 16^{2+}$ & 883.9631 & 883.9617 & 1.6 \\
\hline $\mathrm{y} 17^{2+}$ & 925.4817 & 925.4804 & 1.4 \\
\hline $\mathrm{y} 18^{2+}$ & 975.0159 & 975.0141 & 1.8 \\
\hline $\mathrm{y} 19^{2+}$ & 1010.5344 & 1010.5326 & 1.8 \\
\hline $\mathrm{y} 20^{2+}$ & 1060.0686 & 1060.0670 & 1.6 \\
\hline $\mathrm{y} 21^{2+}$ & 1088.5794 & 1088.5774 & 1.8 \\
\hline $\mathrm{y} 22^{2+}$ & 1153.1007 & 1153.0988 & 1.6 \\
\hline $\mathrm{y} 23^{2+}$ & 1201.6271 & 1201.6248 & 1.9 \\
\hline $\mathrm{y} 24^{2+}$ & 1243.1456 & 1243.1437 & 1.5 \\
\hline $\mathrm{b} 4$ & 435.2966 & 435.2960 & 1.2 \\
\hline $\mathrm{b} 5$ & 506.3337 & 506.3330 & 1.3 \\
\hline $\mathrm{b} 6$ & 577.3708 & 577.3700 & 1.5 \\
\hline $\mathrm{b} 7$ & 690.4549 & 690.4537 & 1.6 \\
\hline $\mathrm{b} 8$ & 761.4920 & 761.4911 & 1.2 \\
\hline $\mathrm{b} 9$ & 844.5291 & 844.5277 & 1.7 \\
\hline $\mathrm{b} 12^{2+}$ & 564.3269 & 564.3261 & 1.5 \\
\hline $\mathrm{b} 13^{2+}$ & 613.8611 & 613.8601 & 1.6 \\
\hline $\mathrm{b} 14^{2+}$ & 649.3796 & 649.3785 & 1.7 \\
\hline & & & \\
\hline
\end{tabular}


A

Pegvadin A (Streptomyces noursei)

IIIPI)

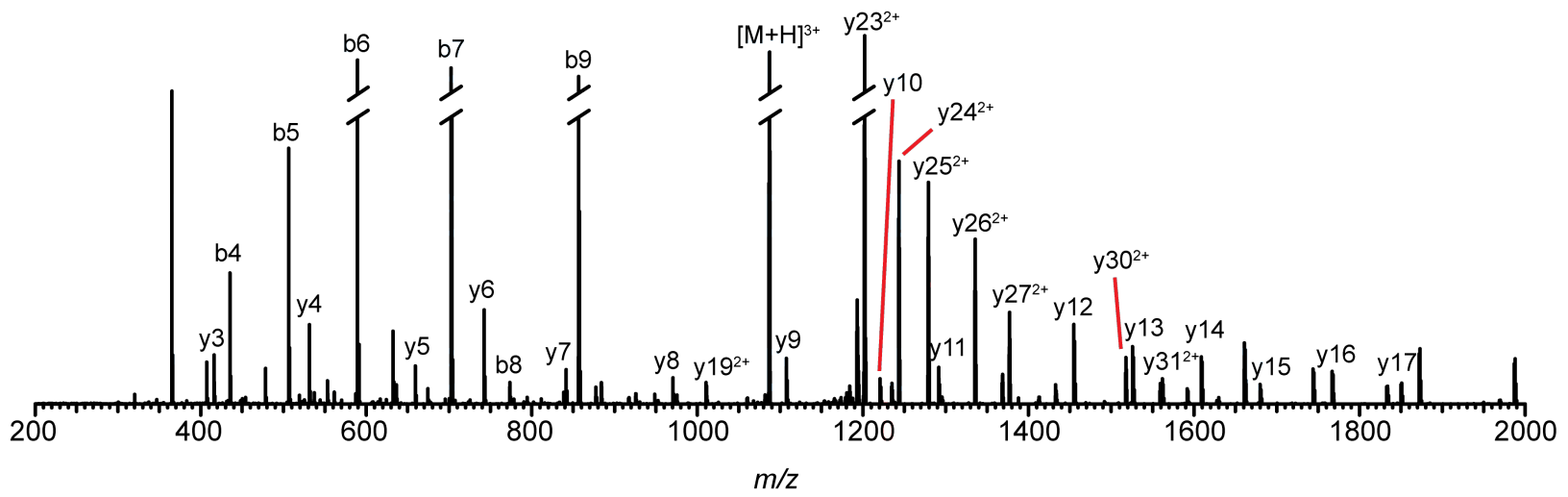

B

Pegvadin B (Streptomyces auratus)
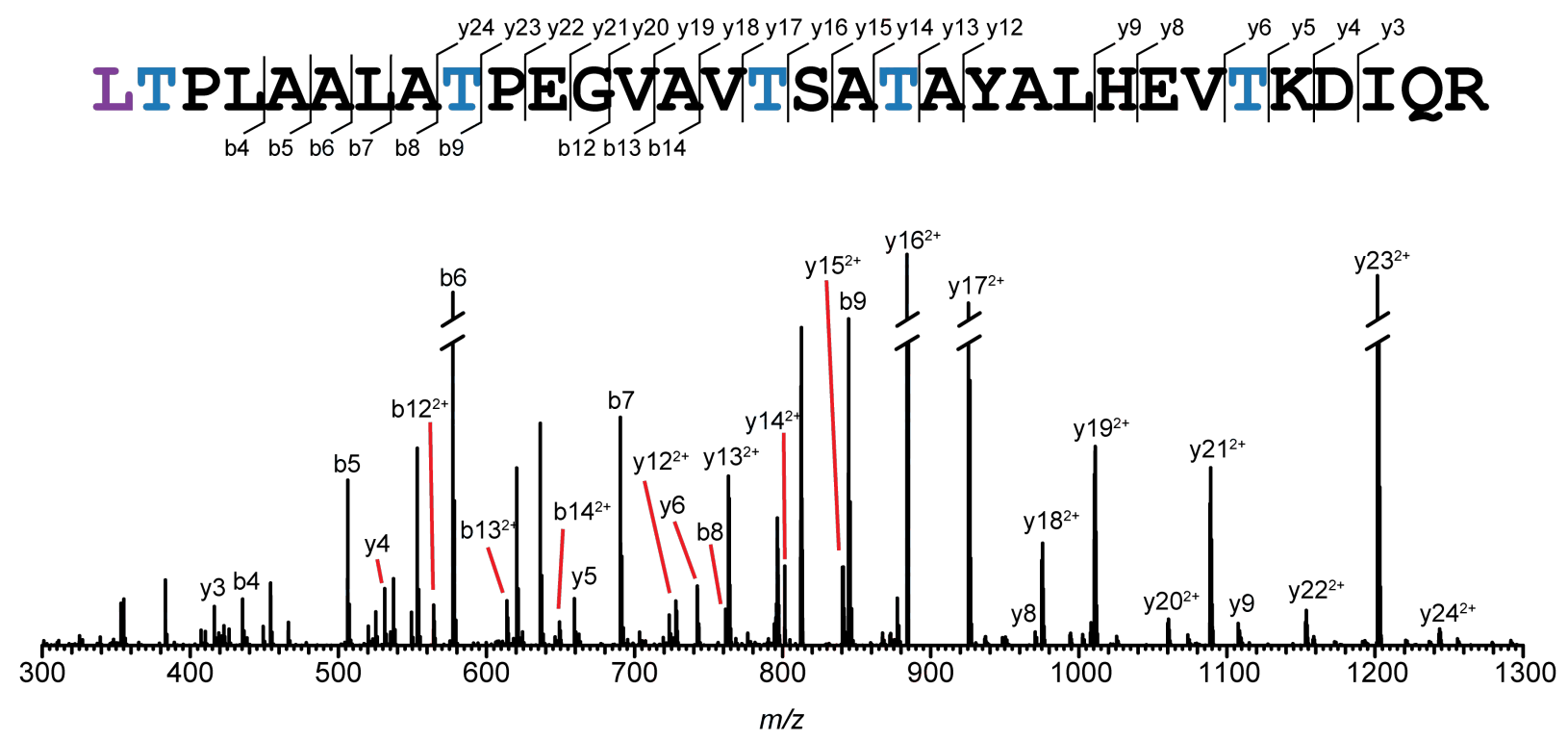

Figure S16: High-resolution and tandem mass spectrometry of pegvadins $A$ and $B$. HRMS/MS data for pegvadin A (A) and pegvadin B (B). Fragmentation yielded $b$ and $y$ ions consistent with the sequence of the precursor peptides. Blue, Thr position was converted to Dhb; purple, dimethylated $\mathrm{N}$-terminus. 
Table S10: Sequence identity/similarity comparison of enzymes in characterized linaridin BGCs. Sequences were aligned with MAFFT and identity/similarity was assessed using the Sequence Identity And Similarity tool (http://imed.med.ucm.es/Tools/sias.html). Yellow, \% identity; Green, \% similarity.

\begin{tabular}{|l|r|r|r|r|r|r|}
\hline LinE Protein & $\mathbf{1}$ & $\mathbf{2}$ & $\mathbf{3}$ & $\mathbf{4}$ & $\mathbf{5}$ & $\mathbf{6}$ \\
\hline 1. Streptomyces noursei (WP_073444435.1) & 100 & 79 & 69 & 31 & 31 & 28 \\
\hline 2. Streptomyces auratus (WP_040898716.1) & 83 & 100 & 66 & 31 & 29 & 28 \\
\hline 3. Streptomyces sp. CT34 (WP_078894000.1) & 76 & 74 & 100 & 31 & 30 & 29 \\
\hline 4. Streptomyces sp. OH-4156 (ADR72963.1) & 44 & 43 & 43 & 100 & 82 & 68 \\
\hline 5. Streptomyces barkulensis (WP_101256404.1) & 43 & 42 & 42 & 87 & 100 & 71 \\
\hline 6. Streptomyces griseus (WP_003970681.1) & 40 & 39 & 39 & 77 & 77 & 100 \\
\hline
\end{tabular}

\begin{tabular}{|l|r|r|r|r|r|r|}
\hline LinG Protein & $\mathbf{1}$ & $\mathbf{2}$ & $\mathbf{3}$ & $\mathbf{4}$ & $\mathbf{5}$ & $\mathbf{6}$ \\
\hline 1. Streptomyces noursei (WP_067348450.1) & 100 & 92 & 84 & 33 & 31 & 31 \\
\hline 2. Streptomyces auratus (WP_040898719.1) & 95 & 100 & 86 & 33 & 31 & 30 \\
\hline 3. Streptomyces sp. CT34 (WP_043265482.1) & 88 & 88 & 100 & 31 & 30 & 30 \\
\hline 4. Streptomyces sp. OH-4156 (ADR72963.1) & 45 & 44 & 42 & 100 & 84 & 84 \\
\hline 5. Streptomyces barkulensis (WP_101256404.1) & 43 & 43 & 41 & 88 & 100 & 78 \\
\hline 6. Streptomyces griseus (WP_003970681.1) & 45 & 44 & 44 & 87 & 83 & 100 \\
\hline
\end{tabular}

\begin{tabular}{|l|r|r|r|r|r|r|}
\hline LinL Protein & $\mathbf{1}$ & $\mathbf{2}$ & $\mathbf{3}$ & $\mathbf{4}$ & $\mathbf{5}$ & $\mathbf{6}$ \\
\hline 1. Streptomyces noursei (WP_099055705.1) & 100 & 29 & 28 & 26 & 27 & 26 \\
\hline 2. Streptomyces auratus (WP_106430490.1) & 38 & 100 & 70 & 37 & 33 & 31 \\
\hline 3. Streptomyces sp. CT34 (WP_078894692.1) & 38 & 76 & 100 & 36 & 33 & 35 \\
\hline 4. Streptomyces sp. OH-4156 (ADR72964.1) & 37 & 46 & 46 & 100 & 87 & 74 \\
\hline 5. Streptomyces barkulensis (WP_101256405.1) & 37 & 44 & 44 & 89 & 100 & 76 \\
\hline 6. Streptomyces griseus (WP_003970680.1) & 37 & 40 & 44 & 81 & 81 & 100 \\
\hline
\end{tabular}

\begin{tabular}{|l|r|r|r|r|r|r|}
\hline LinM (Methyltransferase) & $\mathbf{1}$ & $\mathbf{2}$ & $\mathbf{3}$ & $\mathbf{4}$ & $\mathbf{5}$ & $\mathbf{6}$ \\
\hline 1. Streptomyces noursei (WP_067348459.1) & 100 & 85 & 87 & 25 & 22 & 21 \\
\hline 2. Streptomyces auratus (WP_040898722.1) & 88 & 100 & 83 & 26 & 24 & 20 \\
\hline 3. Streptomyces sp. CT34 (WP_107068144.1) & 89 & 87 & 100 & 28 & 25 & 23 \\
\hline 4. Streptomyces sp. OH-4156 (ADR72966.1) & 32 & 34 & 33 & 100 & 85 & 76 \\
\hline 5. Streptomyces barkulensis (WP_101256407.1) & 30 & 31 & 32 & 89 & 100 & 76 \\
\hline 6. Streptomyces griseus (WP_012381886.1) & 30 & 30 & 32 & 83 & 84 & 100 \\
\hline
\end{tabular}

\begin{tabular}{|l|r|r|r|r|r|r|}
\hline LinT (ABC Transporter) & $\mathbf{1}$ & $\mathbf{2}$ & $\mathbf{3}$ & $\mathbf{4}$ & $\mathbf{5}$ & $\mathbf{6}$ \\
\hline 1. Streptomyces noursei (WP_102926632.1) & 100 & 74 & 77 & 21 & 22 & 23 \\
\hline 2. Streptomyces auratus (WP_040900283.1) & 79 & 100 & 80 & 17 & 19 & 19 \\
\hline 3. Streptomyces sp. CT34 (WP_052230046.1) & 83 & 85 & 100 & 18 & 20 & 20 \\
\hline 4. Streptomyces sp. OH-4156 (ADR72968.1) & 30 & 26 & 28 & 100 & 78 & 61 \\
\hline 5. Streptomyces barkulensis (WP_101256409.1) & 31 & 28 & 29 & 82 & 100 & 62 \\
\hline 6. Streptomyces griseus (WP_012381885.1) & 30 & 25 & 27 & 70 & 70 & 100 \\
\hline
\end{tabular}


A

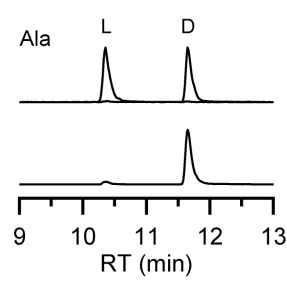

Gly
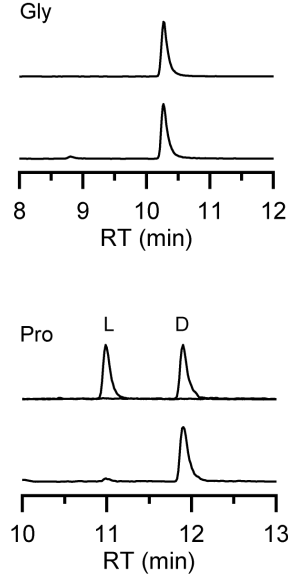

B
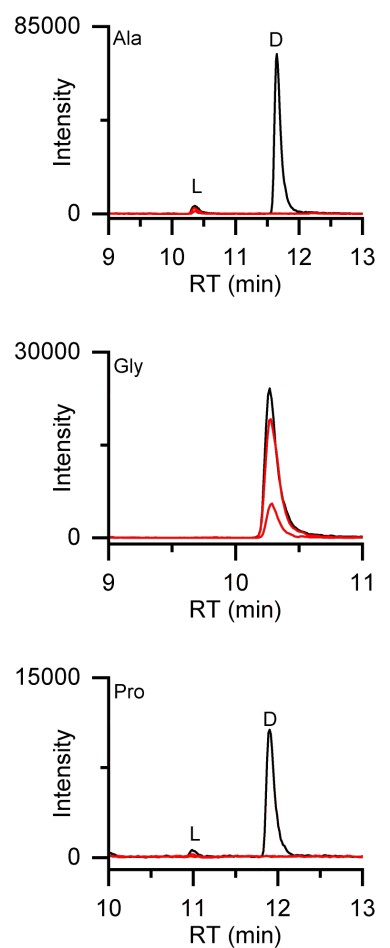
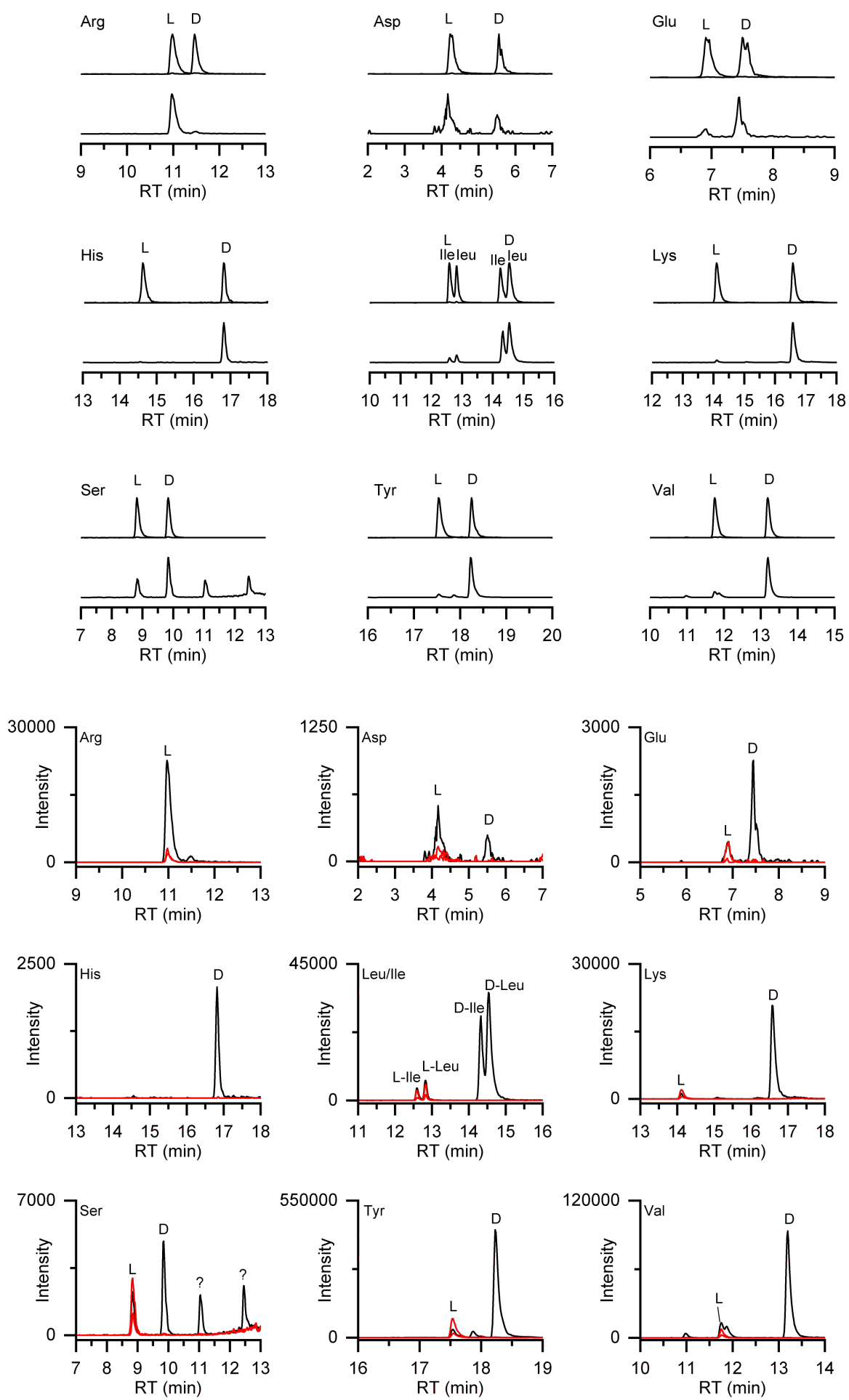

Figure S17: Marfey's stereochemical analysis of pegvadin A. (A) Intensity-normalized LCMRM-MS chromatograms of FDAA-labeled amino acid standards (top) and pegvadin A hydrolysate (bottom). (B) Non-normalized LC-MRM-MS chromatograms of FDAA-labeled hydrolysed pegvadin A (black) and a blank hydrolysis reaction (red). 
Table S11: Statistical analysis of pegvadin A stereochemical data. The core sequence of pegavadin A is comprised of: Ala (6), Arg (1), Asp (1), Gln (1), Glu (2), Gly (1), His (1), Ile (1), Leu (4, with one dimethylated), Lys (1), Pro (2), Ser (1), Thr (6, all as Dhb), Tyr (1), Val (3). Primary sequence: LTPLATLATPEGVAVTSATAYALHEVTKDIQR.

\begin{tabular}{|c|c|c|c|c|c|c|l|}
\hline $\begin{array}{c}\text { Amino } \\
\text { acid }\end{array}$ & $\begin{array}{c}\text { L-peak } \\
\text { area }\end{array}$ & $\begin{array}{c}\text { D-Peak } \\
\text { area }\end{array}$ & $\begin{array}{c}\text { D/(L+D)×100 } \\
\text { (\%) } \\
\text { uncorrected) }\end{array}$ & $\begin{array}{c}\text { L-peak area } \\
\text { labeling } \\
\text { blank, run 1 }\end{array}$ & $\begin{array}{c}\text { L-peak area } \\
\text { labeling } \\
\text { blank, run 2 }\end{array}$ & $\begin{array}{c}\text { Stereochem } \\
\text { result }\end{array}$ & Notes \\
\hline Ala & 524 & 9017 & 94.5 & 336 & 149 & D-isomer & No D-Ala peak detected in labeling blanks. \\
\hline Arg & 3316 & 213 & 6.0 & 325 & 237 & L-isomer & No D-Arg peak detected in labeling blanks. \\
\hline Asx & 97 & 38 & 28.1 & 40 & 20 & Inconclusive & Low intensity. No D-Asx detected in blanks. \\
\hline Glx & 57 & 242 & 80.9 & 51 & 9 & D-isomer & $\begin{array}{l}\text { Low intensity. No D-Glx peak detected in } \\
\text { blanks. Likely only D-Glx in peptide. }\end{array}$ \\
\hline His & 0 & 206 & 100.0 & 0 & 0 & D-isomer & $\begin{array}{l}\text { Low intensity, only D-His was detected. No } \\
\text { L-His or D-His detected in blanks. }\end{array}$ \\
\hline Ile & 404 & 2998 & 88.1 & 320 & 100 & D-isomer & No D-lle peak detected in blanks. \\
\hline Leu & 612 & 5425 & 89.9 & 456 & 162 & D-isomer & $\begin{array}{l}\text { Observed ratio is 1.8:1 Leu:lle, rather than } \\
\text { predicted 3:1 Leu:lle. No D-Leu detected in } \\
\text { blanks. }\end{array}$ \\
\hline Lys & 141 & 3045 & 95.6 & 297 & 74 & D-isomer & No D-Lys detected in blanks. \\
\hline Pro & 78 & 1312 & 94.4 & 44 & 17 & D-isomer & No D-Pro detected in blanks. \\
\hline Ser & 287 & 590 & 67.3 & 425 & 136 & D-isomer & $\begin{array}{l}\text { Presence of L-Ser is attributed to } \\
\text { background. No D-Ser detected in blanks. }\end{array}$ \\
\hline Tyr & 3414 & 43716 & 92.8 & 8544 & 1800 & D-isomer & No D-Tyr detected in blanks. \\
\hline Val & 1416 & 11234 & 88.8 & 825.1 & 284 & D-isomer & No D-Val detected in blanks. \\
\hline
\end{tabular}




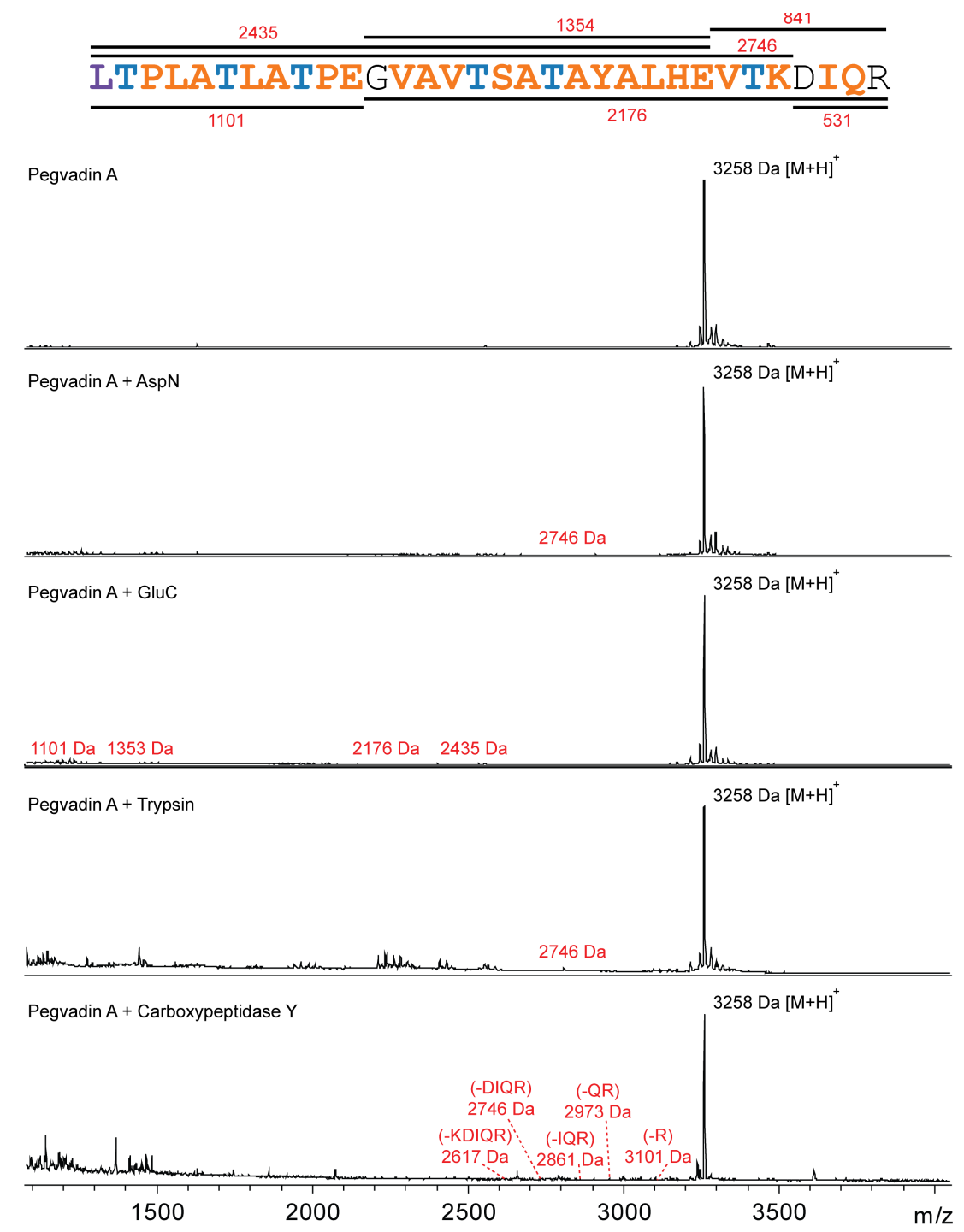

Figure S18: Proteolytic susceptibility of pegvadin A. The primary amino acid sequence of pegvadin $A$ is given with purple, blue, and orange representing sites of dimethylation, Dhb formation, and epimerization to the D-amino acid based on Marfey's analysis. The horizontal lines represent expected proteolytic fragments (and mass values in red) after treatment with endoproteinase Asp-N, Glu-C, and trypsin. MALDI-TOF mass spectra of pegvadin A after $24 \mathrm{~h}$ of treatment with the noted proteases. In all cases, the most intense ion was the undigested parental mass, indicating substantial proteolytic resistance. No ions were observed at masses corresponding to the expected cleavage sites (red) for any of the tested proteases. 


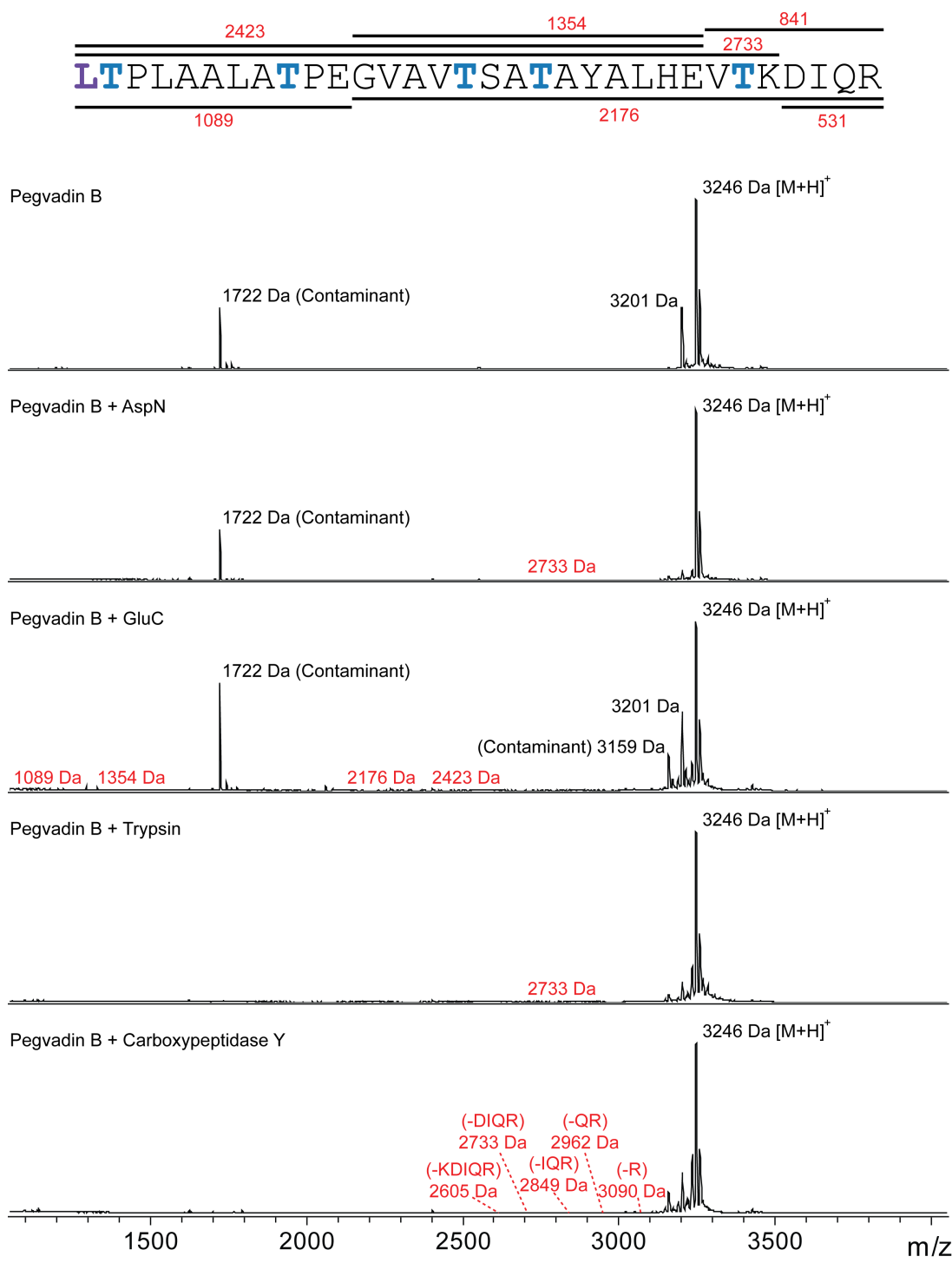

Figure S19: Proteolytic susceptibility of pegvadin B. The primary amino acid sequence of pegvadin B is given with purple and blue representing sites of dimethylation and Dhb formation, respectively. The horizontal lines represent expected proteolytic fragments (and mass values in red) after treatment with endoproteinase Asp-N, Glu-C, and trypsin. MALDI-TOF mass spectra of partially purified pegvadin B (note impurities at $\mathrm{m} / \mathrm{z} 1722$ and 3159 , and $3201 \mathrm{Da}$ ) after $24 \mathrm{~h}$ of treatment with the noted proteases. In all cases, the most intense ion was the undigested parental mass, indicating substantial proteolytic resistance. No ions were observed at masses corresponding to the expected cleavage sites (red) for any of the tested proteases. 
Table S12: Bioactivity assessment of pegvadin A.

\begin{tabular}{|l|l|c|c|l|}
\hline Genus/species & Strain & MIC $(\boldsymbol{\mu g} / \mathbf{m L})$ & MIC $(\boldsymbol{\mu M})$ & $\begin{array}{l}\text { Positive control } \\
(\mathbf{M I C}, \mu \mathbf{g} / \mathbf{m L})\end{array}$ \\
\hline Staphylococcus aureus & USA300 & $>32$ & $>9.8$ & Tetracycline $(1)$ \\
Pseudomonas aeuroginosa & PA01 & $>32$ & $>9.8$ & Tetracycline $(0.5)$ \\
Micrococcus luteus & DSM1790 & $>32$ & $>9.8$ & Chloramphenicol (4) \\
Streptomyces puniceus & B-2895 & $>32$ & $>9.8$ & Kanamycin (1) \\
\hline
\end{tabular}




\section{Supplemental References}

(1) Altschul, S. Gapped BLAST and PSI-BLAST: A New Generation of Protein Database Search Programs. Nucleic Acids Res. 1997, 25 (17), 3389-3402.

(2) Tietz, J. I.; Schwalen, C. J.; Patel, P. S.; Maxson, T.; Blair, P. M.; Tai, H.-C.; Zakai, U. I.; Mitchell, D. A. A New Genome-Mining Tool Redefines the Lasso Peptide Biosynthetic Landscape. Nat. Chem. Biol. 2017, 13 (5), 470-478.

(3) Mistry, J.; Finn, R. D.; Eddy, S. R.; Bateman, A.; Punta, M. Challenges in Homology Search: HMMER3 and Convergent Evolution of Coiled-Coil Regions. Nucleic Acids Res. 2013, 41 (12), e121-e121.

(4) Katoh, K.; Standley, D. M. MAFFT Multiple Sequence Alignment Software Version 7: Improvements in Performance and Usability. Mol. Biol. Evol. 2013, 30 (4), 772-780.

(5) El-Gebali, S.; Mistry, J.; Bateman, A.; Eddy, S. R.; Luciani, A.; Potter, S. C.; Qureshi, M.; Richardson, L. J.; Salazar, G. A.; Smart, A.; Sonnhammer, E. L. L.; Hirsh, L.; Paladin, L.; Piovesan, D.; Tosatto, S. C. E.; Finn, R. D. The Pfam Protein Families Database in 2019. Nucleic Acids Res. 2019, 47 (D1), D427-D432.

(6) Haft, D. H. The TIGRFAMs Database of Protein Families. Nucleic Acids Res. 2003, 31 (1), 371373.

(7) Grant, C. E.; Bailey, T. L.; Noble, W. S. FIMO: Scanning for Occurrences of a given Motif. Bioinformatics 2011, 27 (7), 1017-1018.

(8) Atkinson, H. J.; Morris, J. H.; Ferrin, T. E.; Babbitt, P. C. Using Sequence Similarity Networks for Visualization of Relationships Across Diverse Protein Superfamilies. PLoS ONE 2009, 4 (2), e4345.

(9) Zallot, R.; Oberg, N.; Gerlt, J. A. The EFI Web Resource for Genomic Enzymology Tools: Leveraging Protein, Genome, and Metagenome Databases to Discover Novel Enzymes and Metabolic Pathways. Biochemistry 2019, 58 (41), 4169-4182.

(10) Shannon, P. Cytoscape: A Software Environment for Integrated Models of Biomolecular Interaction Networks. Genome Res. 2003, 13 (11), 2498-2504.

(11) Price, M. N.; Dehal, P. S.; Arkin, A. P. FastTree 2 - Approximately Maximum-Likelihood Trees for Large Alignments. PLoS ONE 2010, 5 (3), e9490. https://doi.org/10.1371/journal.pone.0009490.

(12) Letunic, I.; Bork, P. Interactive Tree Of Life (ITOL) v4: Recent Updates and New Developments. Nucleic Acids Res. 2019, 47 (W1), W256-W259.

(13) Jones, P.; Binns, D.; Chang, H.-Y.; Fraser, M.; Li, W.; McAnulla, C.; McWilliam, H.; Maslen, J.; Mitchell, A.; Nuka, G.; Pesseat, S.; Quinn, A. F.; Sangrador-Vegas, A.; Scheremetjew, M.; Yong, S.Y.; Lopez, R.; Hunter, S. InterProScan 5: Genome-Scale Protein Function Classification. Bioinformatics 2014, 30 (9), 1236-1240.

(14) Soding, J.; Biegert, A.; Lupas, A. N. The HHpred Interactive Server for Protein Homology Detection and Structure Prediction. Nucleic Acids Res. 2005, 33 (Web Server), W244-W248.

(15) Ma, S.; Zhang, Q. Linaridin Natural Products. Nat. Prod. Rep. 2020, 10.1039.C9NP00074G.

(16) Jiang, Y.; Li, Q.; Chen, X.; Jiang, C. Isolation and Cultivation Methods of Actinobacteria. In Actinobacteria - Basics and Biotechnological Applications; Dhanasekaran, D., Jiang, Y., Eds.; InTech, 2016.

(17) van Wezel, G. P.; McDowall, K. J. The Regulation of the Secondary Metabolism of Streptomyces: New Links and Experimental Advances. Nat. Prod. Rep. 2011, 28 (7), 1311.

(18) Balch, W. E.; Fox, G. E.; Magrum, L. J.; Woese, C. R.; Wolfe, R. S. Methanogens: Reevaluation of a Unique Biological Group. Microbiol Rev 1979, 43 (2), 260-296.

(19) Rateb, M. E.; Zhai, Y.; Ehrner, E.; Rath, C. M.; Wang, X.; Tabudravu, J.; Ebel, R.; Bibb, M.; Kyeremeh, K.; Dorrestein, P. C.; Hong, K.; Jaspars, M.; Deng, H. Legonaridin, a New Member of Linaridin RiPP from a Ghanaian Streptomyces Isolate. Org. Biomol. Chem. 2015, 13 (37), 95859592.

(20) Livnat, I.; Tai, H.-C.; Jansson, E. T.; Bai, L.; Romanova, E. V.; Chen, T.; Yu, K.; Chen, S.; Zhang, Y.; Wang, Z.; Liu, D.; Weiss, K. R.; Jing, J.; Sweedler, J. V. A D -Amino Acid-Containing Neuropeptide Discovery Funnel. Anal. Chem. 2016, 88 (23), 11868-11876.

(21) de los Santos, E. L. C. NeuRiPP: Neural Network Identification of RiPP Precursor Peptides. Sci. Rep. 2019, 9 (1), 13406.

(22) Merwin, N. J.; Mousa, W. K.; Dejong, C. A.; Skinnider, M. A.; Cannon, M. J.; Li, H.; Dial, K.; Gunabalasingam, M.; Johnston, C.; Magarvey, N. A. DeepRiPP Integrates Multiomics Data to 
Automate Discovery of Novel Ribosomally Synthesized Natural Products. Proc. Natl. Acad. Sci. 2020, 117 (1), 371-380.

(23) Cao, L.; Gurevich, A.; Alexander, K. L.; Naman, C. B.; Leão, T.; Glukhov, E.; Luzzatto-Knaan, T.; Vargas, F.; Quinn, R.; Bouslimani, A.; Nothias, L. F.; Singh, N. K.; Sanders, J. G.; Benitez, R. A. S.; Thompson, L. R.; Hamid, M.-N.; Morton, J. T.; Mikheenko, A.; Shlemov, A.; Korobeynikov, A.; Friedberg, I.; Knight, R.; Venkateswaran, K.; Gerwick, W. H.; Gerwick, L.; Dorrestein, P. C.; Pevzner, P. A.; Mohimani, H. MetaMiner: A Scalable Peptidogenomics Approach for Discovery of Ribosomal Peptide Natural Products with Blind Modifications from Microbial Communities. Cell Syst. 2019, 9 (6), 600-608.e4.

(24) Agrawal, P.; Khater, S.; Gupta, M.; Sain, N.; Mohanty, D. RiPPMiner: A Bioinformatics Resource for Deciphering Chemical Structures of RiPPs Based on Prediction of Cleavage and Cross-Links. Nucleic Acids Res. 2017, 45 (W1), W80-W88.

(25) Ding, W.; Yuan, N.; Mandalapu, D.; Mo, T.; Dong, S.; Zhang, Q. Cypemycin Decarboxylase CypD Is Not Responsible for Aminovinyl-Cysteine (AviCys) Ring Formation. Org. Lett. 2018, 20 (23), 7670-7673.

(26) Crooks, G. E. WebLogo: A Sequence Logo Generator. Genome Res. 2004, 14 (6), 1188-1190.

(27) Arnison, P. G.; Bibb, M. J.; Bierbaum, G.; Bowers, A. A.; Bugni, T. S.; Bulaj, G.; Camarero, J. A.; Campopiano, D. J.; Challis, G. L.; Clardy, J.; Cotter, P. D.; Craik, D. J.; Dawson, M.; Dittmann, E.; Donadio, S.; Dorrestein, P. C.; Entian, K.-D.; Fischbach, M. A.; Garavelli, J. S.; Göransson, U.; Gruber, C. W.; Haft, D. H.; Hemscheidt, T. K.; Hertweck, C.; Hill, C.; Horswill, A. R.; Jaspars, M.; Kelly, W. L.; Klinman, J. P.; Kuipers, O. P.; Link, A. J.; Liu, W.; Marahiel, M. A.; Mitchell, D. A.; Moll, G. N.; Moore, B. S.; Müller, R.; Nair, S. K.; Nes, I. F.; Norris, G. E.; Olivera, B. M.; Onaka, H.; Patchett, M. L.; Piel, J.; Reaney, M. J. T.; Rebuffat, S.; Ross, R. P.; Sahl, H.-G.; Schmidt, E. W.; Selsted, M. E.; Severinov, K.; Shen, B.; Sivonen, K.; Smith, L.; Stein, T.; Süssmuth, R. D.; Tagg, J. R.; Tang, G.-L.; Truman, A. W.; Vederas, J. C.; Walsh, C. T.; Walton, J. D.; Wenzel, S. C.; Willey, J. M.; van der Donk, W. A. Ribosomally Synthesized and Post-Translationally Modified Peptide Natural Products: Overview and Recommendations for a Universal Nomenclature. Nat Prod Rep 2013, 30 (1), 108-160. 